\title{
Spatiotemporal Characterization of the Cellular and Molecular Contributors to Liver Fibrosis in a Murine Hepatotoxic-Injury Model
}

Michelle Melino, ${ }^{*}$ Victoria L. Gadd, ${ }^{\dagger}$ Kylie A. Alexander, ${ }^{*}$ Lynette Beattie, ${ }^{*}$ Katie E. Lineburg, ${ }^{*}$ Michelle Martinez, ${ }^{*}$ Bianca Teal, ${ }^{*}$ Laetitia Le Texier, ${ }^{*}$ Katharine M. Irvine, ${ }^{\dagger}$ Gregory C. Miller, ${ }^{\ddagger}$ Glen M. Boyle, ${ }^{\S}$ Geoffrey R. Hill, ${ }^{*}$ Andrew D. Clouston, ${ }^{\dagger \S \ddagger}$ Elizabeth E. Powell, ${ }^{\ddagger}$ and Kelli P.A. MacDonald ${ }^{*}$

From the Departments of Immunology* and Cell and Molecular Biology, ${ }^{\S}$ QIMR Berghofer Medical Research Institute, Brisbane, Queensland; the Centre for Liver Disease Research, ${ }^{\dagger}$ The University of Queensland, Brisbane, Queensland; Envoi Specialist Pathologists, ${ }^{\ddagger}$ Brisbane, Queensland; and the Department of Gastroenterology and Hepatology," Princess Alexandra Hospital, Brisbane, Queensland, Australia

Accepted for publication October 27, 2015.

Address correspondence to Kelli P.A. MacDonald, Ph.D. QIMR Berghofer Medical Research Institute, 300 Herston Rd, Brisbane 4006, Australia. E-mail: kelli. macdonald@qimrberghofer. edu.au.

\begin{abstract}
The interplay between the inflammatory infiltrate and tissue resident cell populations invokes fibrogenesis. However, the temporal and mechanistic contributions of these cells to fibrosis are obscure. To address this issue, liver inflammation, ductular reaction (DR), and fibrosis were induced in $\mathrm{C} 57 \mathrm{BL} / 6$ mice by thioacetamide administration for up to 12 weeks. Thioacetamide treatment induced two phases of liver fibrosis. A rapid pericentral inflammatory infiltrate enriched in $\mathrm{F} 4 / 80^{+}$monocytes co-localized with $\mathrm{SMA}^{+}$myofibroblasts resulted in early collagen deposition, marking the start of an initial fibrotic phase ( 1 to 6 weeks). An expansion of bone marrow-derived macrophages preceded a second phase, characterized by accelerated progression of fibrosis ( $>6$ weeks) after DR migration from the portal tracts to the centrilobular site of injury, in association with an increase in DR/macrophage interactions. Although chemokine (C-C motif) ligand 2 (CCL2) mRNA was induced rapidly in response to thioacetamide, CCL2 deficiency only partially abrogated fibrosis. In contrast, colony-stimulating factor 1 receptor blockade diminished C-C chemokine receptor type 2 [CCR2 ${ }^{\text {neg }}\left(\right.$ Ly6C $\left.^{\text {lo }}\right)$ ] monocytes, attenuated the DR, and significantly reduced fibrosis, illustrating the critical role of colonystimulating factor 1-dependent monocyte/macrophage differentiation and linking the two phases of injury. In response to liver injury, colony-stimulating factor 1 drives early monocyte-mediated myofibroblast activation and collagen deposition, subsequent macrophage differentiation, and their association with the advancing DR, the formation of fibrotic septa, and the progression of liver fibrosis to cirrhosis. (Am J Pathol 2016, 186: 524-538; http://dx.doi.org/10.1016/j.ajpath.2015.10.029)
\end{abstract}

Chronic liver disease is a growing worldwide health problem that is aggravated by the lack of effective therapies. Chronic inflammation contributes to fibrosis, which is common to almost all forms of liver injury independent of the etiology. Inflammation is associated with leukocyte infiltration, and the interplay between the inflammatory infiltrate and resident liver cell populations (eg, biliary epithelial cells, hepatic stellate cells, and Kupffer cells) invokes fibrogenesis, which can lead to cirrhosis, liver failure, and hepatocellular carcinoma. Several histological patterns of fibrosis can be distinguished, including portal and septal fibrosis (inherent to progressive liver disease) and centrilobular fibrosis (a feature of steatohepatitis), suggesting the existence of multiple distinct fibrogenic pathways. ${ }^{1}$ To date, the relationship between the cellular mediators driving these pathways remains unclear.

Progressive portal and septal fibrosis is associated closely with a ductular reaction (DR). ${ }^{2-4}$ The DR is a complex of strings of cholangiocytes and bile ductules, in a niche of stromal and inflammatory cells at the portal tract

Supported by the National Health and Medical Research Council of Australia (APP1044650). K.P.A.M. is a Cancer Council QLD Senior Research Fellow, E.E.P. is an NHMRC Practitioner Fellow, and K.M.I. is an Australian Liver Foundation Fellow.

A.D.C., E.E.P., and K.P.A.M. contributed equally as senior authors.

Disclosure: None declared. 
interface. $^{4-6}$ These reactive ductules contain hepatic progenitor cells (HPC), which are small bipotential cells capable of proliferation, migration, and differentiation into either hepatocytes or cholangiocytes when mature hepatocyte proliferation is impaired or inadequate. ${ }^{2}$ Somewhat paradoxically, the DR appears to be central to both hepatobiliary regeneration, as well as changes in the extracellular matrix and progressive fibrogenesis. ${ }^{7}$ The signals responsible for the induction and progression of the DR remain unclear, and a persisting question in the field is whether the DR directly promotes fibrosis or whether matrix deposition is intrinsic to HPC expansion., $3,7,8$

Monocytes and macrophages are established as critical mediators of fibrosis, although the nature of the specific myeloid population(s), their temporal contribution, and the mechanism by which these cells promote fibrosis remain undefined. Hepatic macrophages play a pivotal role in the activation of stellate cells and promotion of matrix accumulation during injury. ${ }^{9}$ Additionally, macrophages contribute to matrix remodeling as they are an important source of matrix metalloproteinases and also can generate several extracellular matrix components. ${ }^{10,11}$ Thus, through their diverse functionality, macrophages can both promote and limit fibrosis. In this regard, in response to toxic liver injury, recruited inflammatory $\mathrm{Gr}^{+}$monocytes were shown not only to promote fibrosis, ${ }^{12}$ but also to differentiate into restorative macrophages during resolution, ${ }^{13}$ suggesting that the liver microenvironment is key in instructing macrophage function. Macrophages together with myofibroblasts also are key components of the inflammatory niche that forms around the DR and may provide a link between liver injury and liver repair and regeneration. In diseased human liver ${ }^{14,15}$ and rodent models of liver injury, ${ }^{16}$ macrophages associate intimately with HPC and may facilitate DR expansion. ${ }^{7,17-19}$ Although the epithelial component of the niche has been examined closely, minimal data are available regarding the inflammatory stroma. Additionally, the mechanism of inflammatory cell recruitment and the phenotype of the recruited monocyte or macrophages remain unclear.

The current studies investigated the temporal cellular interplay that occurs during active hepatocellular fibrogenesis induced by chronic administration of the hepatotoxin, thioacetamide (TAA). Oral administration of TAA leads to centrilobular necrosis and induces a gradual progressive fibrosis permissive of temporal analysis of the cellular and molecular contributors to the fibrogenic process. Additionally, hepatocellular carcinoma manifests in this model after long-term TAA treatment mimicking the inflammation, fibrosis, and malignancy disease progression that occurs in patients. ${ }^{20} \mathrm{We}$ undertook a comprehensive time course analysis, characterizing the development of inflammation, fibrosis, and DR, and identified two phases of liver fibrosis. An early phase was characterized by pericentral monocyte infiltration associated with myofibroblast activation and localized collagen deposition, whereas a later phase was characterized by tissue resident macrophage turnover, the development of a mature DR, and extensive organwide fibrosis. Examination of the cytokine and chemokine requirement of the monocytes and macrophages established colony-stimulating factor 1 (CSF-1) and, to a lesser degree, chemokine (C-C motif) ligand 2 (CCL2) as key mediators of early- and late-stage liver fibrosis. Taken together, the data highlight multiple potential cellular and molecular targets to explore for the development of more efficacious therapeutics for the treatment of liver fibrosis.

\section{Materials and Methods}

\section{Mice}

Female C57BL/6 (B6.WT) mice were purchased from the Animal Resource Center (Perth, Australia). B6.CCL2 ${ }^{-1-}$, B.6. $\mathrm{CCR} 2^{-1-}$, and B6.Collagen 1(A) luciferase mice (B6.Coll 1A$\mathrm{luc}^{+}$) were supplied by the QIMR Berghofer Medical Research Institute animal facility (Brisbane, Queensland, Australia). All mice used were 6 to 12 weeks of age, housed in microisolator cages, and received normal chow. Mice were treated with or without TAA (Sigma-Aldrich, St. Louis, MO) supplemented in the drinking water at $300 \mathrm{mg} / \mathrm{L}$ for 1 to 12 weeks. For $\mathrm{F} 4 / 80^{+}$characterization, naive and TAA-treated mice were injected intravenously with $100 \mu \mathrm{g}$ of fluorescein isothiocyanate (FITC)-dextran (2,000,000 MW; Life Technologies, Grand Island, NY) before TAA treatment or 24 hours before harvest. For CSF-1 blockade experiments, mice received three injections per week of $400 \mu \mathrm{g}$ of anti-CSF1R antibody (M279; Amgen, Thousand Oaks, CA) or RatIgG control antibody via intraperitoneal injection for 4 weeks in conjunction with TAA treatment. Approval for all mouse experiments and procedures was obtained from the Institutional Animal Ethics Committees of the QIMR Berghofer Medical Research Institute (Brisbane, Australia).

\section{Histology}

Murine livers were harvested, preserved in $10 \%$ formalin, and embedded in paraffin or immersed in $30 \%$ sucrose for 48 hours and frozen in Tissue-Tek O.C.T compound (Sakura Finetek, Torrance, CA). Hematoxylin and eosin and Sirius red single stains were performed, and histological changes (inflammatory infiltrate and fibrosis) were assessed by two experienced hepatopathologists (G.C.M and A.D.C). Fibrosis stage was assessed using a modified METAVIR score as previously described. ${ }^{21}$ Briefly, stage 1 , periportal or centrilobular fibrosis; stage 2, some septa; stage 3, many septa; and stage 4 , cirrhosis.

\section{Immunostaining}

Deparaffinized liver tissue-sections were immunolabeled, as described previously. ${ }^{14}$ Wide-spectrum keratin (CK-WSS; bile duct, ductular epithelium and HPC), F4/80 (macrophages), $\alpha$-smooth muscle actin (SMA; activated stellate cells and myofibroblasts), and Col1-A1 (fibrosis). CK-WSS (1:400 IHC dilution, 1:100 IF dilution, catalog \#Z0622, 
Dako, Glostrup, Denmark), $\alpha$-SMA (1:100 dilution IHC, catalog \#M0851, Dako), and Col1-A1 (1:200 IHC dilution, catalog \# SB131001, Southern Biotech, Birmingham, AL) underwent heat-induced antigen retrieval $(10 \mathrm{mmol} / \mathrm{L}$ Tris Base/1 mmol/L EDTA solution, pH9), whereas F4/80 (1:200 IHC dilution, 1:300 IF dilution, MCA497GA, AbD Serotec, Kidlington, UK) required enzymatic digestion (Carezyme Trypsin, Biocare Medical, Concord, CA). Slides stained by immunohistochemical methods underwent virtual microscopy (ScanScope XT Slide Scanner, Aperio, Vista, CA) and were analyzed with ImageScope software version 11.2 (Aperio). Sirius red-stained collagen fibers were quantified by Aperio analysis algorithm. A total of three separate areas 5 to $10 \mathrm{~mm}^{2}$ were analyzed for each sample, excluding the capsule and portal tracts larger than $150 \mu \mathrm{m}$. Fluorescent microscopy was performed using the Zeiss LSM 510 Meta confocal microscope (Carl Zeiss Australia, North Ryde, Australia). To assess the relationship between macrophages and the DR, two representative animals from time points 0 to 12 weeks were co-stained with F4/80 and CK-WSS. Macrophages were counted as either the number of $\mathrm{F} 4 / 80^{+}$cells touching the $\mathrm{CK}-\mathrm{WSS}^{+}$cells of the DR or $\mathrm{F} 4 / 80^{+}$cells not contacting the DR, in 10 random $20 \times$ fields from each section. The percentage of $\mathrm{F} 4 / 80^{+}$cells making direct contact with the DR was calculated.

\section{Bioluminescence Imaging}

Following TAA treatment at the time points indicated, B6.Coll $1 \mathrm{~A}-\mathrm{luc}^{+}$mice were injected subcutaneously with $0.5 \mathrm{mg}$ luciferin (Sigma-Aldrich) and then anesthetized with isoflurane for 5 minutes. Livers were harvested before imaging using the Xenogen imaging system (Xenogen IVIS 100; Caliper Life Sciences, Hopkinton, MA). Data were analyzed with Living Image software version 4 (Caliper Life Sciences, Hopkinton, MA).

\section{RNA Isolation and RT-PCR Analysis}

Total RNA was extracted from murine liver tissue using TRI Reagent (Sigma-Aldrich), and RNA quality was assessed using the Agilent 2100 Bioanalyser (Agilent Technologies, Santa Clara, CA). Complimentary DNA was generated using SuperScript III Reverse Transcriptase (Life Technologies). Col1-A1 and MCP-1 mRNA expression were measured using predesigned Taqman gene expression assays (Life Technologies) and reverse-transcription PCR was performed on a ViiA 7 Real-Time PCR System (Life Technologies). All measurements were normalized against the expression of the housekeeping gene, HPRT.

\section{Isolation of Hepatic Leukocytes}

The hepatic leukocyte fraction was isolated as described previously with minor modifications. ${ }^{22}$ Briefly, livers were perfused with $10 \mathrm{~mL}$ phosphate-buffered saline via the portal vein and minced finely with surgical scissors. Liver fragments were then pushed through a $200-\mu \mathrm{mol} / \mathrm{L}$ gauge stainless steel mesh with the addition of $14 \mathrm{~mL}$ of Hank's based salt solution containing $1 \mathrm{mg} / \mathrm{mL}$ Collagenase Type III (D) (Worthington Biochemical Corporation, Lakewood, NJ), $1 \mu \mathrm{g} / \mathrm{mL}$ DNase I (Sigma), $100 \mathrm{U} / \mathrm{mL}$ penicillin, and $100 \mu \mathrm{g} / \mathrm{mL}$ streptomycin. The cell suspension was incubated at $37^{\circ} \mathrm{C}$ for 5 minutes before the addition of $0.01 \mathrm{~mol} / \mathrm{L}$ EDTA. After an additional 5-minute incubation period, total liver cells were pressed through a $70-\mu \mathrm{mol} / \mathrm{L}$ cell strainer (Becton Dickinson Australia, North Ryde, Australia), washed twice in cold phosphatebuffered saline containing 2\% heat-inactivated fetal bovine serum, resuspended in $25 \mathrm{~mL}$ of $33 \%$ Percoll (GE Healthcare Life Sciences, Piscataway, NJ) in phosphate-buffered saline, and centrifuged at $600 \times g$ for 15 minutes with no break. All supernatant was discarded, and the resulting cell pellet was lyzed for 2 minutes in Gey's solution, washed twice, and resuspended in cold phosphate-buffered saline containing $2 \%$ heat-inactivated fetal bovine serum.

\section{Flow Cytometry}

Freshly isolated hepatic leukocytes $\left(1 \times 10^{6}\right)$ were blocked with 2.4G2 (BD Biosciences, San Diego, CA) for 10 minutes before 30 minutes of staining with the following antibodies purchased from BioLegend (San Diego, CA): FITC-conjugated anti-CD19 (1/100 dilution, clone 6D5), PerCP/Cy5.5-conjugated CD11b (1/100 dilution, clone M1/70), AF647-conjugated TIM4 (1/100 dilution, clone RMT4-54), Pacific Blue-conjugated Ly6C (1/ 100 dilution, clone HK1.4), APC-conjugated CD11c (1/100 dilution, clone N418), APC/Cy7-conjugated Ly6G (1/100 dilution, clone 1A8), PE-conjugated F4/80 (1/100 dilution, clone BM8), PE-CF594-conjugated CD3 (1/100 dilution, clone 17A2), and PE/Cy7-conjugated I-A/I-E (1/300 dilution, clone M5/114.15.2). APC-conjugated CCR2 (1/100 dilution, clone 475301) was purchased from R\&D Systems (Minneapolis, MN). Live cell events were measured on an LSR Fortessa flow cytometer (BD Biosciences) and analyzed with FlowJo software version 10 (Tree Star, Ashland, OR). The absolute number of each cell type was calculated by multiplying the frequency by the total number of viable hepatic leukocytes per liver.

\section{Microarray}

Biotinylated cRNA was prepared from whole liver tissue using the Illumina TotalPrep cRNA Amplification Kit (Ambion, Austin, TX). Mouse Ref-8 v 2.0 arrays (Illumina, San Diego, CA) were hybridized, washed, and scanned with iScan (Illumina, San Diego, CA) according to standard processes and processed from raw images with Beadarray package R (Bioconductor version 3.0, Fred Hutchinson Cancer Research Center, Seattle, WA). ${ }^{23}$ Probes were filtered for quality and reannotated. ${ }^{24}$ Gene set enrichment analysis was performed using CAMERA for R (Bioconductor version 3.0). ${ }^{25}$ 


\section{Statistical Analysis}

Data are presented as means \pm SEM. The $U$ test or unpaired $t$-tests were performed for group comparisons. A two-tailed $P$ value of 0.05 was considered statistically significant. Linear regression was used for association analyses. All statistical analyses were performed using Prism Version 6 software (GraphPad, La Jolla, CA). When mentioned, $n$ indicates the number of biological or independent replicates.

\section{Results}

Temporal Changes in Inflammation, Fibrosis, and DR During TAA-Induced Liver Injury

We examined the temporal changes in fibrosis, inflammatory infiltrate, and the DR during hepatotoxin-induced chronic liver injury. Aperio image analysis of Sirius red staining demonstrated two phases of liver fibrosis: an initial phase ( 1 to 6 weeks) characterized by a gradual increase in collagen deposition and a second phase (6 to 12 weeks) of accelerated progressive fibrosis during which there was a fivefold increase in collagen deposition (Figure 1, B and D). Within 1 week, a distinct pericentral inflammatory infiltrate with associated collagen deposition was evident (Figure 1, A and B). Notably, this occurred in the absence of significant DR with only single CK-WSS ${ }^{+}$HPC evident at the periphery of the portal tracts (Figure 1C). Over the ensuing 2 weeks of TAA treatment, inflammation remained relatively constant; however, there was a gradual progression of the DR, with single HPC as well as strings of cholangiocytes extending from the periportal region toward the centrilobular areas of injury and increasing collagen deposition in the subsinusoidal spaces. By 4 weeks of TAA treatment, there was an increased inflammatory infiltrate, and the DR expanded and extended from the portal tracts through the lobules to central veins. By 6 weeks, the DR was virtually absent from the periportal region, whereas an extensive DR was present in pericentral regions of the liver lobules, forming wide bands of central-central linkage with close association to collagenous septa. At 8 weeks, cirrhosis was evident in all liver samples with architectural disorganization, formation of parenchymal nodules, and extensive fibrous linkage.

\section{$\mathrm{SMA}^{+}$Myofibroblasts Are Associated with Collagen-1 Production and the Developing DR}

After activation, normally quiescent hepatic stellate cells become smooth muscle actin (SMA) ${ }^{+}$proliferating myofibroblasts, in which Type 1 collagen (Col1-A1) expression is markedly increased at both the transcriptional and posttranscriptional levels. Within 1 week of TAA treatment, intense SMA expression was noted in the pericentral regions, and through the ensuing weeks, this staining extended into the centrilobular regions (Figure 2A). As anticipated, the temporal changes in Coll-A staining mirrored that of SMA, with early pericentral staining followed by central-central septation as well as some periportal fibrosis (Figure 2B). Notably, SMA staining declined after 6 weeks, whereas Col1-A1 reached a plateau (data not shown). Investigations of Col1-A1 expression at the transcriptional level were next undertaken utilizing Col1-A1luciferase transgenic mice, which express luciferase off the Col1-A1 promoter, facilitating quantification of Col1A1 production using bioluminescence imaging (IVIS Lumina Series III; Perkin Elmer, Waltham, MA). In this model, changes in bioluminescence recapitulate the expression patterns of the endogenous Col1-A1 gene. Compared with livers from naive mice, which expressed negligible Col1-A1, TAA treatment rapidly induced and incrementally increased the expression of Col1-A1 over a period of 1 to 4 weeks (Figure 2, C and D). By 6 weeks, however, the bioluminescence appeared to decrease, suggesting a tapering and decline in Col1-A1 expression. The peak of Col1-A1 mRNA expression at week 4 and its subsequent decline was confirmed by reverse-transcription PCR (Figure 2E). To investigate the interplay between the $\mathrm{DR}$ and collagen deposition by $\mathrm{SMA}^{+}$cells in the early phase of liver injury, we performed three-color fluorescent immunolabeling with CK-WSS, SMA, and Col1-A1. After 1 week of TAA treatment, a dense accumulation of $\mathrm{SMA}^{+}$cells was observed at the pericentral sites of injury (Figure $2 \mathrm{~F}$ ). As anticipated, these $\mathrm{SMA}^{+}$myofibroblasts co-localized with Col1-A1 staining, highlighting the association of fibroblast activation with collagen deposition in the absence of HPC/DR in pericentral regions during the early stages of liver injury. By 4 weeks of TAA treatment, parts of the DR were associated intimately with $\mathrm{SMA}^{+}$myofibroblasts and Col1-A1 staining (Figure 2F).

\section{Whole Liver mRNA Transcriptome Analysis}

We next performed genome-wide microarray mRNA analysis of whole liver to gain insight into temporal changes in gene expression patterns and functional activity at different stages of fibrotic progression (http://www.ncbi.nlm.nih.gov/geo; accession no. GSE74605). Hierarchical clustering demonstrated clear blocks of differentially expressed genes associated with each time point (naive and 1, 4, and 6 weeks TAA; Figure 3A). Unique lists of differentially expressed genes were generated for each time point using Venn comparisons (Figure 3A), and canonical pathways were identified (Table 1). Suggestive of a role for monocyte/macrophages in the early phase of fibrosis, a functional myeloid signature was implicated at week 1 by the upregulation of genes associated with phagocytosis, inducible nitric oxide synthase and platelet-derived growth factor signaling, and the production of nitric oxide and reactive oxygen species. In contrast, at the 4-week time point, pathways associated with apoptosis and inflammation predominated, whereas by week $6 \mathrm{Wnt}$ signaling and pathways associated with cell and tissue 


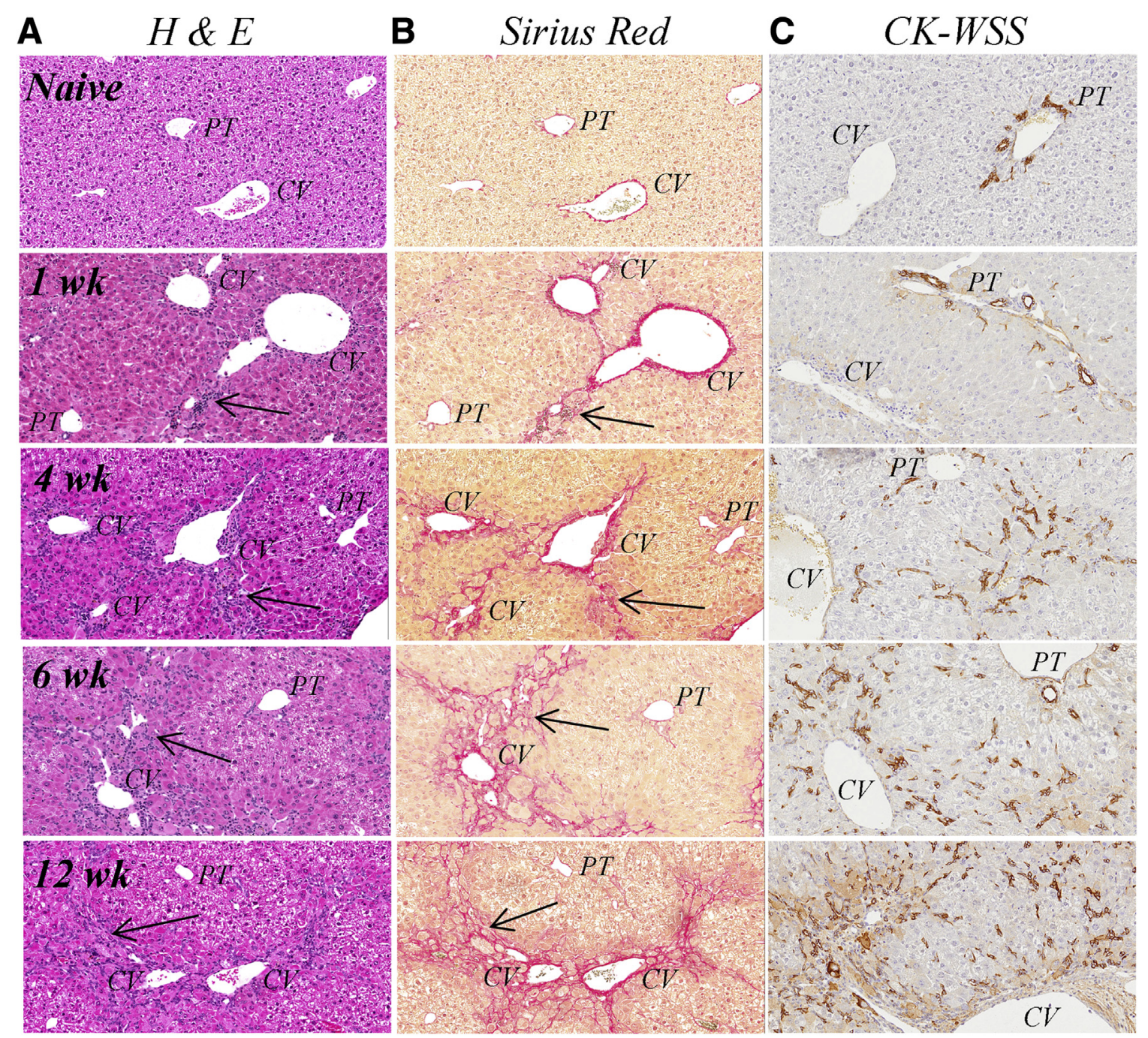

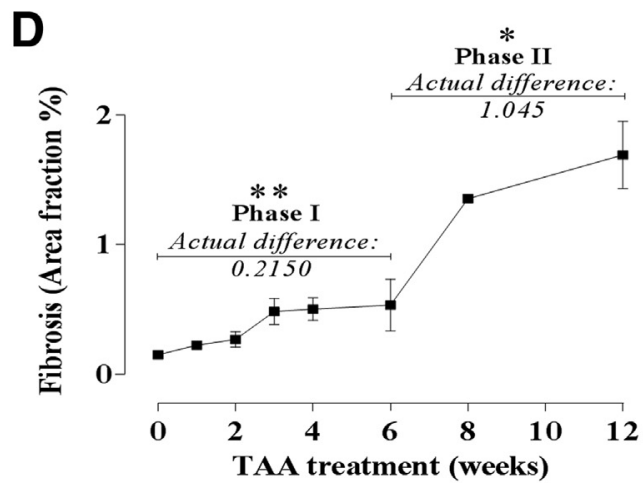

remodeling (Cdc42 signaling and inhibition of matrix metalloproteinases) were highlighted. Notably, of the differentially regulated immune mediator and extracellular matrix component genes identified, over $75 \%$ were temporally regulated (Figure 3B). The monokine Ccl4 and its receptor C cr 5 were upregulated at week 1 , suggesting that this chemokine signaling axis is prominent during early fibrosis. In contrast, matrix metalloproteinases, tissue inhibitors of
Figure 1 Time course analysis of liver inflammation, fibrosis, and the ductular reaction (DR) during thioacetamide (TAA)-induced liver injury. A-C: Histochemical staining for inflammation (hematoxylin and eosin [H\&E]) (A), fibrosis (Sirius red) (B), and immunolabeling for the DR (wide-spectrum keratin [CK-WSS]) (C) in representative liver sections from naive and TAA-treated $\mathrm{C} 57 \mathrm{BL} / 6$ mice. Black arrows indicate inflammatory/fibrotic regions. D: Aperio quantification of Sirius red staining ( $n=6$ to 19 animals per time point). Data are presented as means \pm SEM. ${ }^{*} P<0.05$ ( 0 versus 6 weeks TAA), ${ }^{* *} P<0.01$ ( 6 versus 12 weeks TAA), Mann Whitney $U$ test. CV, central vein; PT, portal tract.

metalloproteinases, and collagen species were upregulated as injury progressed. Additionally, tumor necrosis factor-like weak inducer of apoptosis receptor (Tnfrsf12a) and Ccl25 were upregulated, in contrast to Ill8 and Il6ra, which were downregulated significantly. Of note, at week 6 , clec $4 f$ (alias the Kupffer cell receptor) ${ }^{26}$ and Timd 4 (expressed on tissue resident Kupffer cells), ${ }^{27}$ were both downregulated (Supplemental Table S1). Thus, taken together, these data 

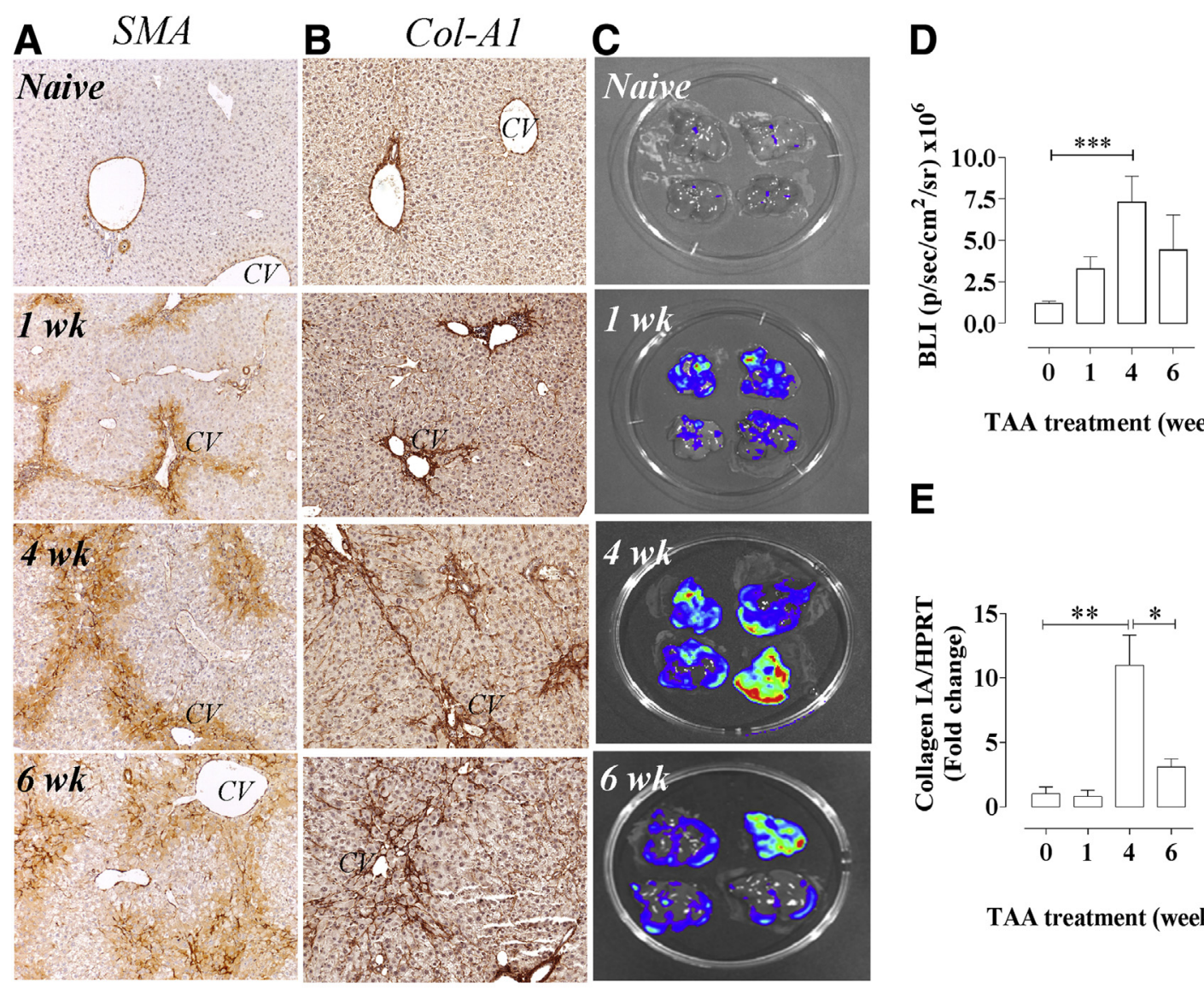

TAA treatment (weeks)

E

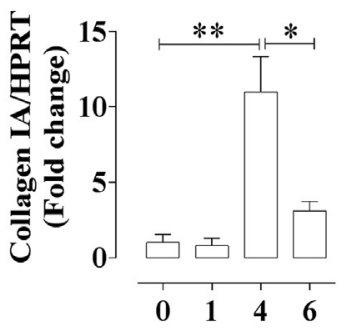

TAA treatment (weeks)

$\mathbf{F}$
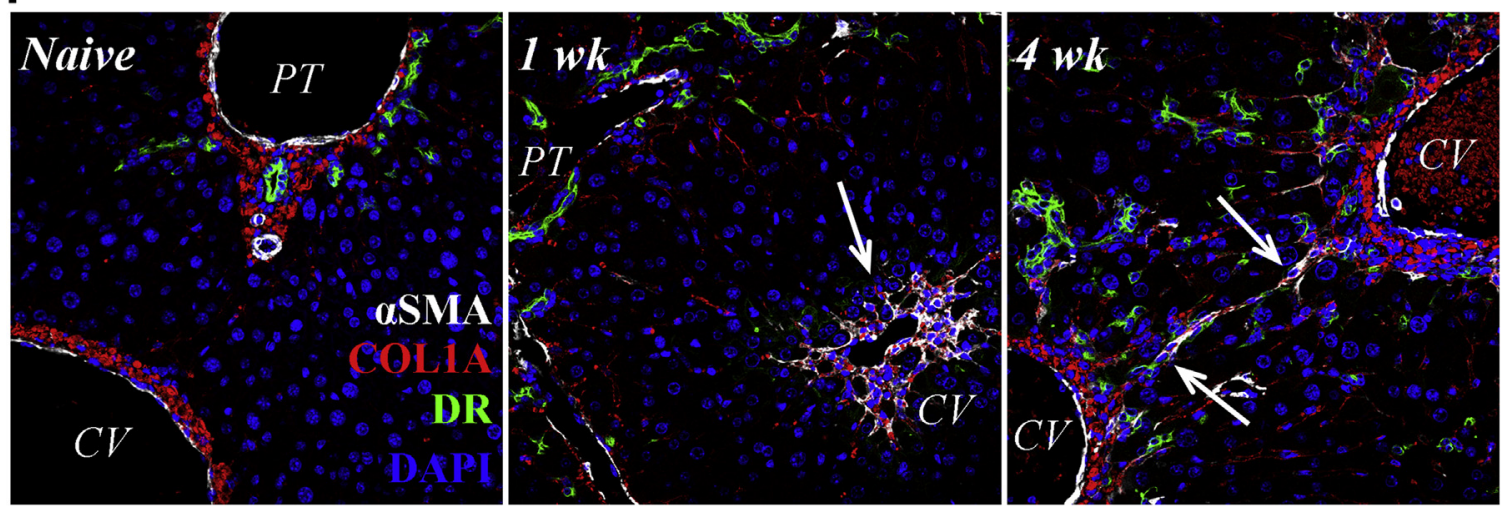

Figure 2 Time course analysis of myofibroblast activation and collagen production during thioacetamide (TAA)-induced liver injury. Immunolabeling for SMA (myofibroblasts) (A) and Collagen-A1 (Col1-A1) (B) in representative liver sections from naive, 1, 4, and 6 weeks TAA-treated mice. Bioluminescence images (C) and analysis (D) from naive and TAA-treated B6. Collagen 1 (A) luciferase mice ( $n=4$ to 12 animals per time point). E: Coll-A1 mRNA expression from naive and TAA-treated mice ( $n=3$ to 7 animals per time point). F: Triple immunofluorescence staining for SMA ${ }^{+}$myofibroblasts (white), Coll-A1 (red), and wide-spectrum keratin (CK-WSS) ${ }^{+}$ductular reaction (green) in representative liver sections from naive, 1 and 4 weeks TAA-treated mice. White arrows indicate fibrotic regions. Data are presented as means \pm SEM. ${ }^{*} P<0.05$ ( 4 versus 6 weeks TAA), ${ }^{* *} P<0.01$ (0 versus 4 weeks TAA), ${ }^{* * *} P<0.001(0$ versus 4 weeks TAA), Mann Whitney $U$ test. CV, central vein; PT, portal tract.

suggest that monocyte/macrophage populations are altered temporally throughout the course of injury.

\section{F4/80 ${ }^{+}$Cells Are Associated with Fibrosis and DR}

Because monocytes/macrophages were shown to be altered temporally, and they also have an established role in activating stromal tissue to promote fibrosis, we examined the association of $\mathrm{F} 4 / 80^{+}$cells with the DR. F4/80 immunolabeling highlighted temporal changes in monocyte and macrophage populations as liver injury progressed (Figure 4A). As expected, naive liver displayed an even distribution of $\mathrm{F} 4 / 80^{+}$monocytes/macrophages throughout the liver lobules, with sparse labeling in the 

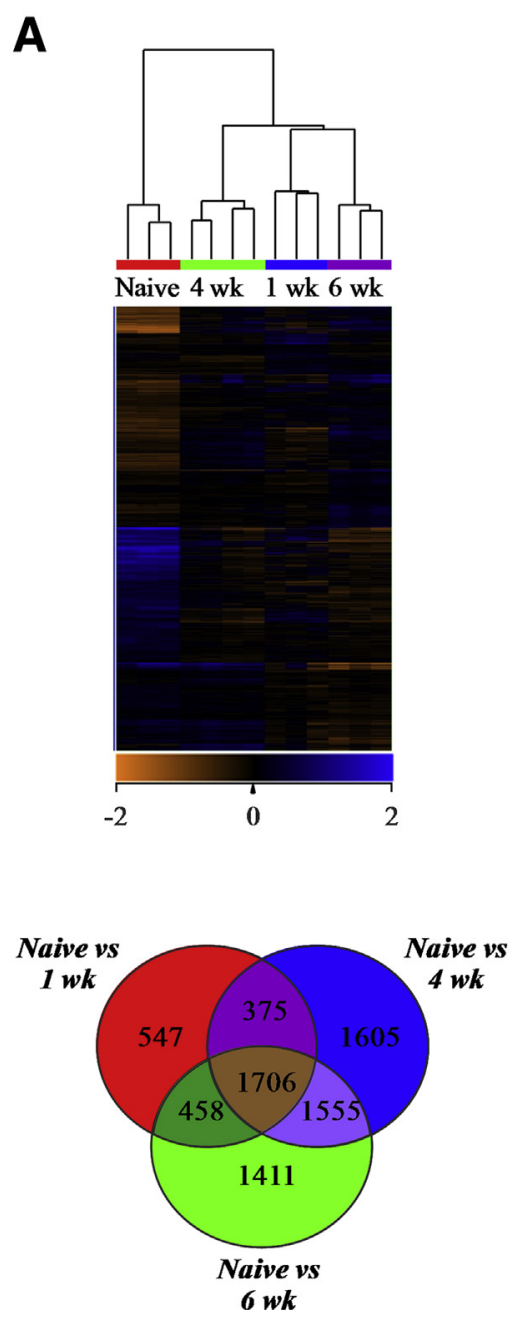

B
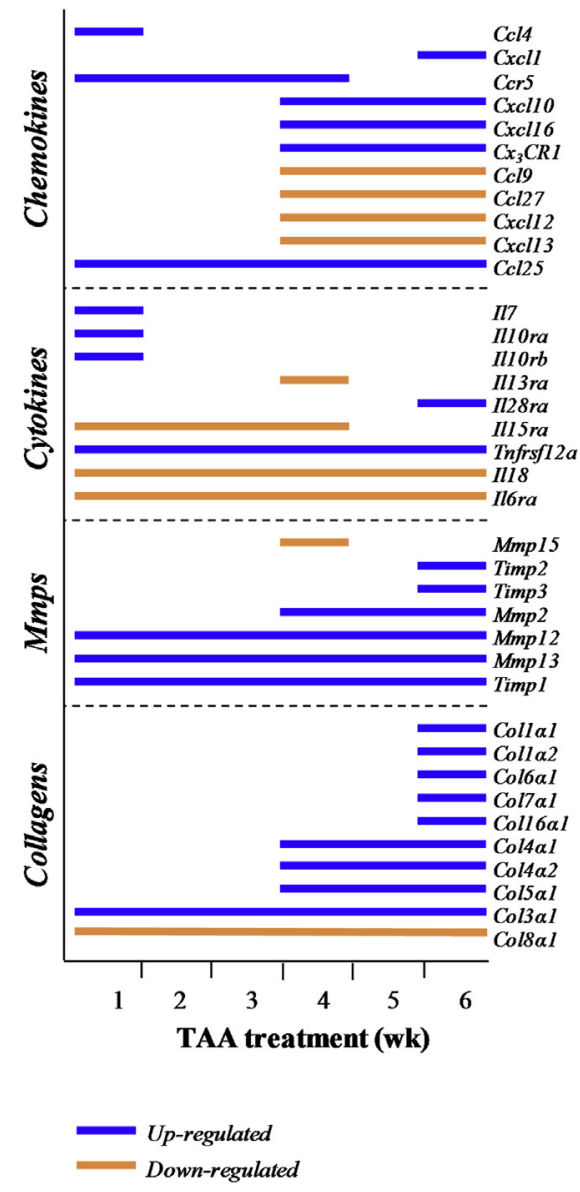

Figure 3 Microarray analysis of livers isolated from naive, 1, 4, and 6 weeks thioacetamide (TAA)-treated mice. A: Genes differentially expressed using one-way analysis of variance, $P<0.05$, were clustered using Euclidian distance metric and Ward's linkage, for visualization. Scale shows difference in fold-expression, and Venn diagram illustrates comparison of differentially expressed genes for whole liver from naive versus 1,4 , and 6 weeks of TAA-treated mice. Red, naive; blue, 1 week TAA; green, 4 weeks TAA; purple, 6 weeks TAA ( $n=3$ to 4 biological replicates per time point). Differentially expressed genes were determined using $t$-test, $P<0.05$. B: Differential expression of chemokines, cytokines, matrix metalloproteinases/tissue inhibitors of metalloproteinases, and collagens with the progression of liver fibrosis. Up-regulated and down-regulated genes are illustrated in blue and orange, respectively. periportal and pericentral regions. Within 1 week of TAA treatment, an increase in the number of $\mathrm{F} 4 / 80^{+}$cells was evident, and notably, there was a striking accumulation of these cells in centrilobular regions of injury (Figure 4, A and C). This accumulation, however, was transient and dissipated by week 3 . By 4 weeks, the distribution of
$\mathrm{F} / 80^{+}$cells was more organized in a central-central distribution. $\mathrm{F} 4 / 80^{+}$cells were rarely in contact with HPC in naive livers (mean 1\%), but this increased by week 3 (mean $5.1 \%$ ), during which migrating ductular structures occasionally were associated with $\mathrm{F} 4 / 80^{+}$cells. However, a strong co-localization between $\mathrm{F} 4 / 80^{+}$cells and the DR,

Table 1 The Top 10 Uniquely Expressed Canonical Pathways as Identified by Ingenuity Pathway Analysis

\begin{tabular}{lll}
\hline Naive versus 1 week & Naive versus 4 weeks & Naive versus 6 weeks \\
\hline Cholesterol biosynthesis & Mitochondrial dysfunction & Protein ubiquitination pathway \\
Tec kinase signaling & 0xidative phosphorylation & Cdc42 signaling \\
Macrophage N0/ROS production & Lymphotoxin $\beta$ receptor signaling & Neurotrophin/TRK signaling \\
iNOS signaling & CD27 signaling in lymphocytes & ATM signaling \\
PI3K/AKT signaling & Regulation of eIF4 and p70S6K & Wnt signaling \\
IL-10 signaling & EIF2 signaling & Inhibition of MMP \\
IL-1 signaling & NRF2-mediated oxidative stress & CDK5 signaling \\
Ephrin receptor signaling & Autophagy & Glucocorticoid signaling \\
EGF signaling & Phagosome maturation & CD28 signaling in T cells \\
PDGF signaling & VEGF signaling & Role of JAK in IL-6 signaling
\end{tabular}

AKT, protein kinase B; ATM, ataxia telangiectasia mutated; EGF, epidermal growth factor; EIF2, eukaryotic initiation factor 2; iNOS, inducible nitric oxide synthase; JAK, janus kinase; MMP, matrix metalloproteinases; NO/ROS, NO/Reactive oxygen species; NRF2, nuclear respiratory factor 2; PDGF, platelet-derived growth factor; PI3K, phosphatidylinositol 3-kinase; Tec, tec protein tyrosine kinase; TRK, tropomyosin receptor kinase; VEGF, vascular endothelial growth factor. 
A
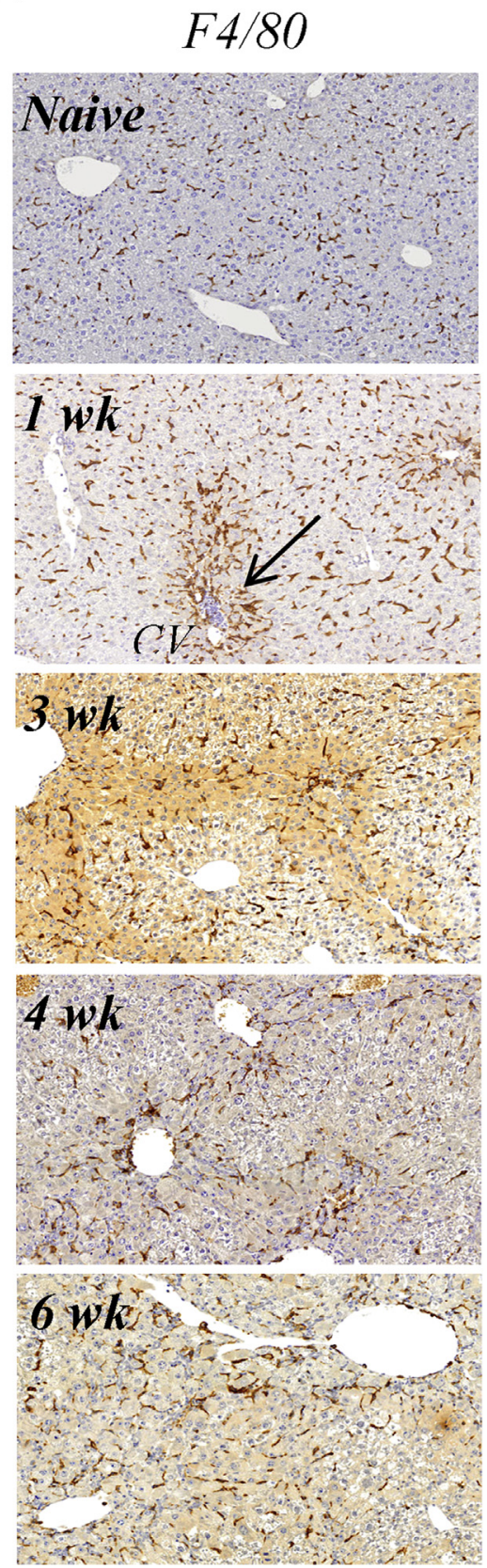

B

\section{F4/80/CK-WSS}
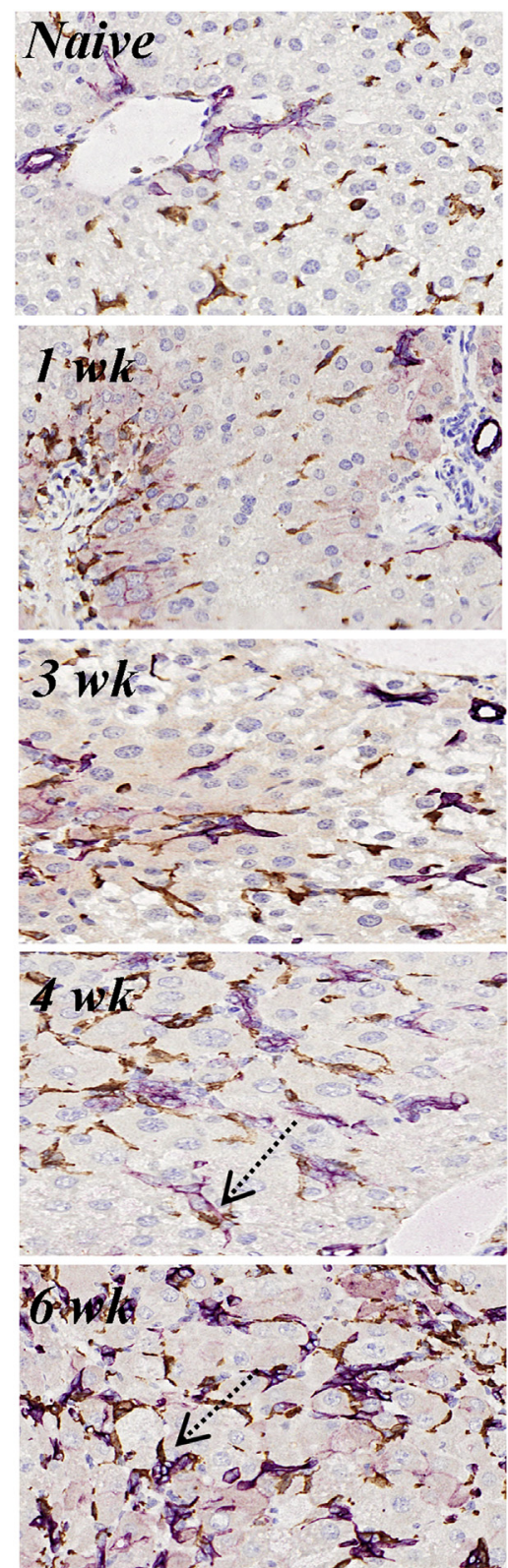

C

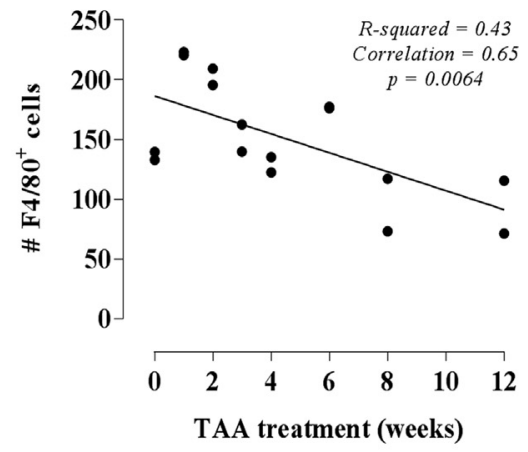

D

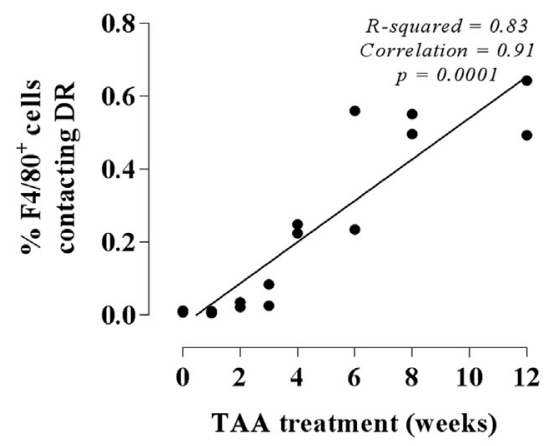

Figure 4 Relationship between $\mathrm{F} 4 / 80^{+}$ cells and the ductular reaction (DR) during liver injury. A and B: Immunolabeling for F4/ $80^{+}$cells $(\mathrm{A})$ and dual staining for $\mathrm{F} 4 / 80^{+}$ cells (brown) + wide-spectrum keratin (CK-WSS) $^{+}$DR (purple) (B) in representative liver sections from naive and thioacetamide (TAA)-treated mice. Black arrow indicates $\mathrm{F} 4 / 80^{+}$accumulation at site of injury and dashed arrows indicate close association between $\mathrm{F} 4 / 80^{+}$cells and the DR. C and $\mathbf{D}$ : Quantification of $\mathrm{F}_{4} / 80^{+}$cells $(\mathrm{C})$ and quantification of $\mathrm{F} / 80^{+}$cells (D) touching widespectrum keratin (CK-WSS) - positive cells from the DR. For both $\mathbf{C}$ and $\mathbf{D}, 10 \times 20$ fields were counted/section ( $n=2$ sections per time point) and linear regression analysis performed. associated with fibrous septa, was observed after 4 weeks of TAA treatment, and this continued to increase for the remainder of the time course (Figure 4, B and D). By 8 weeks, there was a significant increase in DR-associated macrophages with over $50 \%$ of $\mathrm{F} 4 / 80^{+}$cells in direct contact with epithelial cells of the DR.

\section{Characterization of $\mathrm{F} 4 / 80^{+}$Populations}

Because $\mathrm{F} 4 / 80$ is expressed by monocytes as well as tissue resident and bone marrow-derived macrophages within the liver, we next characterized the phenotype of the $\mathrm{F} 4 / 80^{+}$ populations after 1 and 4 weeks of TAA treatment. Flow cytometric analysis of liver mononuclear cells demonstrated two distinct $\mathrm{F} 4 / 80^{+}$populations including $\mathrm{F} 4 / 80^{+} \mathrm{CD} 11 \mathrm{~b}^{\mathrm{hi}}$ monocytes, which were increased significantly at both the 1and 4-week time points, and $\mathrm{F} 4 / 80^{\mathrm{hi}} \mathrm{CD} 11 \mathrm{~b}^{+}$macrophages (Figure 5, A and B). Because the mRNA microarray data indicated that the Kupffer cell gene Timd4 (protein Tim4) was downregulated following TAA treatment, we next examined Tim4 expression by liver macrophages in response to TAA treatment. In naive mice, the liver macrophage pool was comprised of $>90 \% \mathrm{Tim}^{+}{ }^{+}$Kupffer cells with only a small component of bone marrow-derived macrophages (BMDM). Notably, after TAA treatment, the number of BMDM was increased significantly at week 4, and by 6 weeks, BMDM contributed to $80 \%$ of the macrophage pool (Figure 5, C and D). The absolute number 

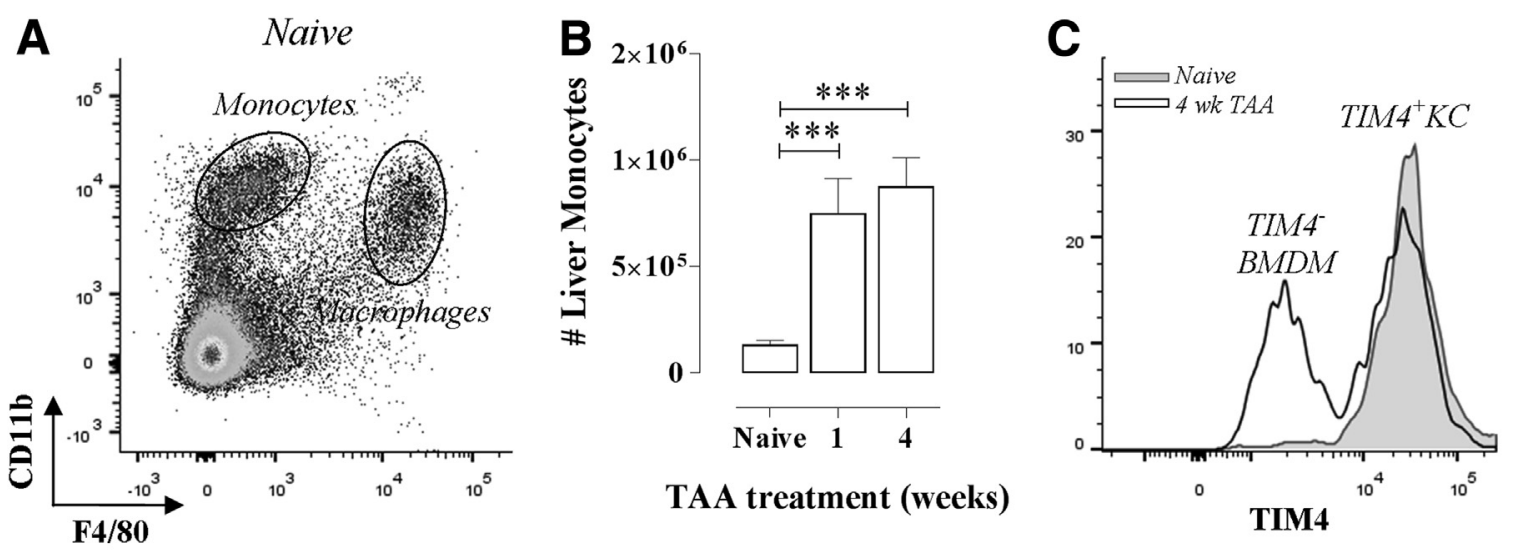

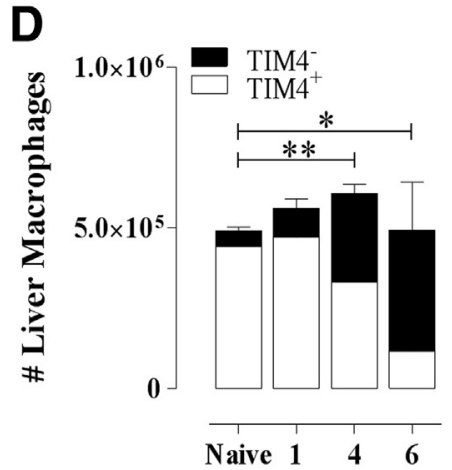

TAA treatment (weeks)

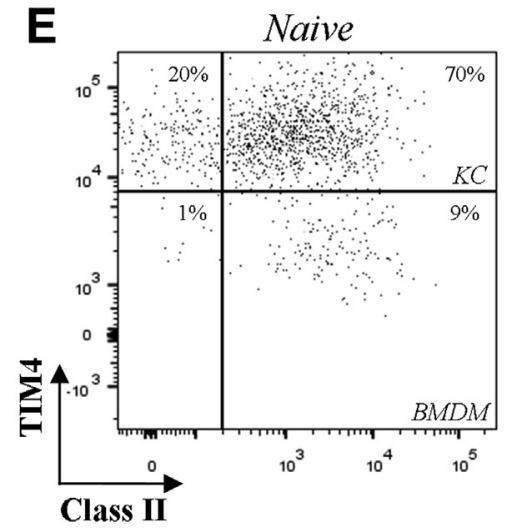

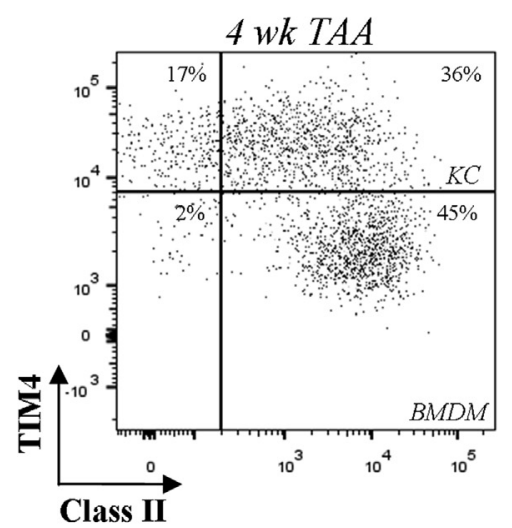

Figure 5 Characterization of $\mathrm{F} 4 / 80^{+}$populations in thioacetamide (TAA)-induced liver injury. A: Representative dot plot illustrating the gating strategy for liver monocytes $\left(\mathrm{F} 4 / 80^{+} \mathrm{CD} 11 \mathrm{~b}^{\mathrm{hi}}\right)$ and macrophages $\left(\mathrm{F} 4 / 80^{\text {hi }} \mathrm{CD} 11 \mathrm{~b}^{+}\right)$. B: Absolute numbers of liver monocytes. C: Representative histogram illustrating TIM4 liver macrophage staining in naive versus 4 weeks TAA-treated mice. D: Absolute numbers of TIM4 ${ }^{+}$liver macrophages (marking KC) and TIM4- liver macrophages (marking BMDM) following TAA treatment ( $n=3$ to 6 samples per time point). E: Representative dot plots illustrating TIM4 and Class II staining in naive and 4 weeks TAA-treated mice. Data are presented as means \pm SEM. ${ }^{*} P<0.05,{ }^{* *} P<0.01$ (TIM4 ${ }^{-}$population; naive versus TAA), ${ }^{* * *} P<0.001$ (naive versus TAA), Mann Whitney $U$ test. BMDM, bone marrow-derived macrophage; KC, Kupffer cell.

of macrophages was not altered significantly, because as BMDM increased, there was a concomitant decrease in Tim $4^{+}$Kupffer cells, such that by 6 weeks, Tim4 ${ }^{+}$Kupffer cells were reduced to $20 \%$ of the macrophage pool. Of note, BMDM expressed higher levels of major histocompatibility complex class II compared with Tim $4^{+}$Kupffer cells suggesting a difference in functionality (Figure $5 \mathrm{E}$ ).

\section{Functional Analysis of $\mathrm{F} 4 / 80^{+}$Populations}

We speculated that the pericentral $\mathrm{F} 4 / 80^{+}$cells noted at the 1 -week time point were likely infiltrating monocytes. To test this, we first established that peripheral blood and liver monocytes could be distinguished from liver macrophages on the basis of their reduced phagocytic capacity in vivo (Figure 6A). Importantly, after 4 weeks of TAA treatment, monocytes remained nonphagocytic, allowing their discrimination from phagocytic macrophages. However, at the 4-week time point, only $60 \%$ of the macrophages were FITC dextran positive, suggesting the emergence of a nonphagocytic macrophage population (Figure 6B). Staining with Tim4 demonstrated that, whereas $\mathrm{Tim}^{+}{ }^{+}$Kupffer cells maintained their phagocytic capacity, BMDM exhibited a significantly reduced capacity to take up FITC dextran in situ (Figure 6C). These data further demonstrated functional differences between tissue resident Kupffer cells and bone marrow-derived macrophages. We next localized FITC dextran-containing F4/80 ${ }^{+}$cells in situ in livers from naive or TAA-treated animals, which had been injected with FITC dextran 18 hours prior. Notably, at 1 week of TAA treatment, the $\mathrm{F} 4 / 80^{+}$cells, which sequestered to the pericentral region, were devoid of FITC dextran. Because nonphagocytic BMDM were not expanded significantly at this time point (Figure 5C), the data indicate that these cells were monocytes (Figure 6D). As anticipated, by 4 weeks, the pericentral monocytic infiltrate was reduced substantially, and $\mathrm{F} 4 / 80^{+}$cells now extended from the central veins into the lobules. In pulse chase experiments, animals were injected with FITC dextran 18 hours before initiation of TAA treatment, and livers were harvested after 1 and 4 weeks of treatment. FITC dextran-labeled cells still were detectable in livers harvested from naive animals 4 weeks after FITC dextran injection (Figure 6E, naive). In TAA-treated animals, however, FITC dextran-labeled cells were detected in livers harvested after 1 week of treatment, but were completely absent at 4 weeks. Taken 

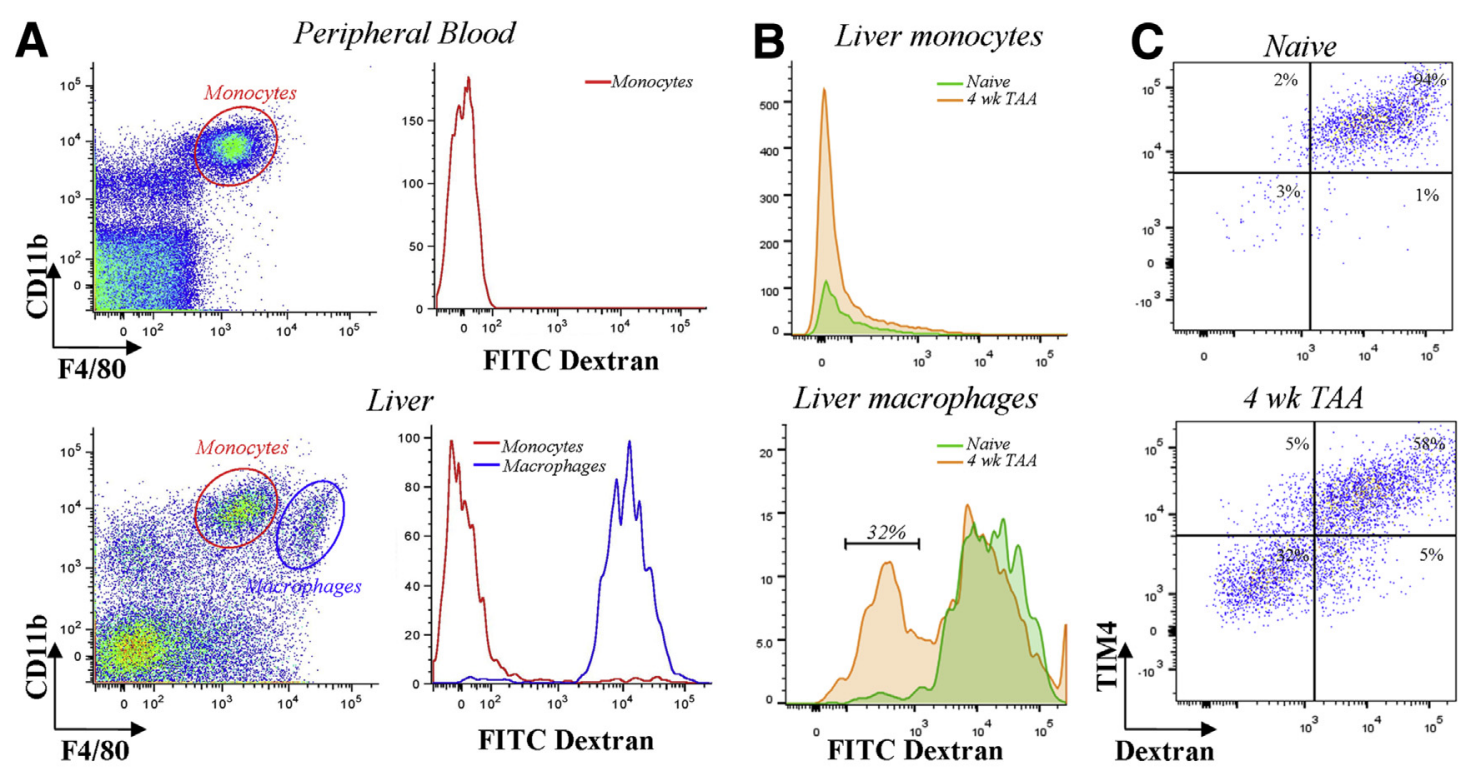

D $18 h r$ pre-harvest
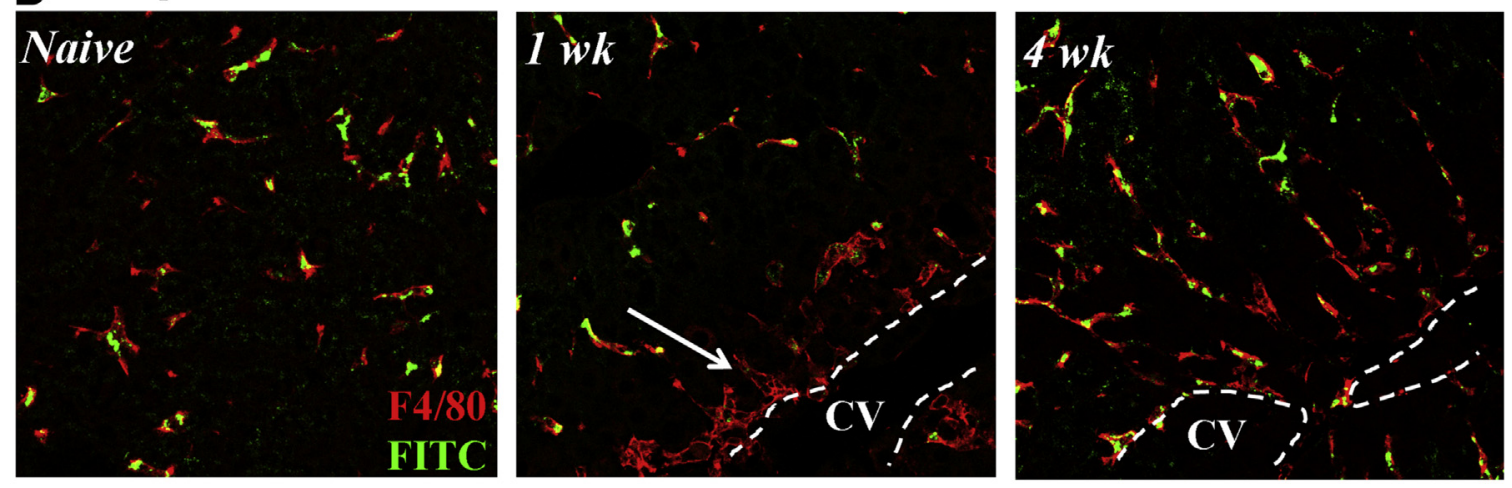

\section{E 18 hr pre-TAA treatment}
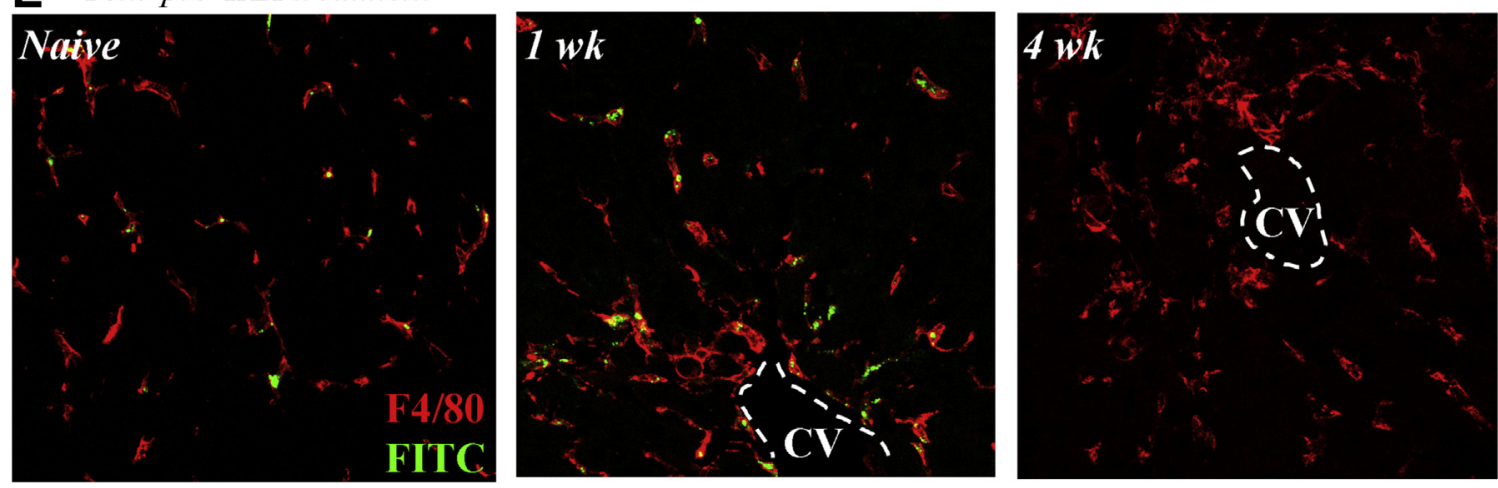

Figure 6 Functional analysis of the $\mathrm{F} 4 / 80^{+}$populations in thioacetamide (TAA)-induced liver injury. A: Representative dot plots illustrating fluorescein isothiocyanate (FITC) dextran uptake in naive peripheral blood and liver. B: Histograms of FITC dextran uptake by liver monocytes and macrophages. C: Comparative dot plots of TIM4 staining and FITC dextran uptake in naive versus 4 weeks TAA-treated mice. D and E: Immunolabeling for F4/80 ${ }^{+}$cells (red) in livers isolated from naive and TAA-treated mice injected with FITC dextran (green) 18 hours preharvest (D) and 18 hours pre-TAA treatment (E). CV, central vein. White arrow indicates monocyte accumulation at central vein.

together with macrophage Tim4 staining, the data confirm the turnover of tissue resident Kupffer cells. We thus demonstrated that TAA treatment rapidly induces the infiltration of monocytes into centrilobular regions of injury where they are poised to differentiate into BMDM to replace tissue resident Kupffer cells.

\section{Characterization of Cytokine Requirements of Infiltrating Monocytes}

Having noted a rapid and significant increase in monocytes within the liver in response to TAA treatment and their localization to the site of early fibrosis, we next examined 

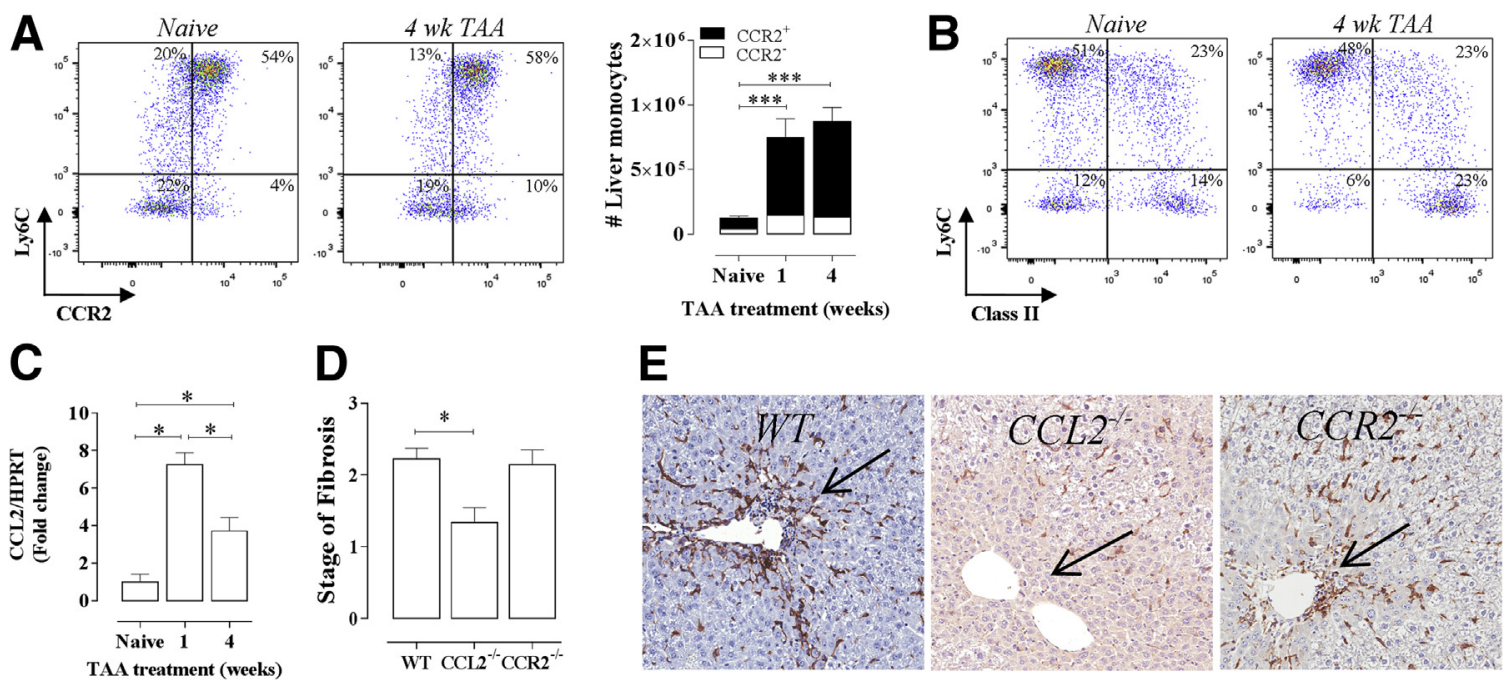

Figure 7 The role of the chemokine ligand (CCL) 2/C-C chemokine receptor type \# (CCR) 2 axis in thioacetamide (TAA)-induced liver injury. A and B: Representative dot plots and quantification of Ly6C/CCR2 (A) and Class II expression in naive versus TAA-treated mice ( $n=6$ to 8 samples per time point) (B). C: CCL2 mRNA expression from naive, 1 , and 4 weeks TAA-treated mice ( $n=4$ to 7 samples per time point). D: Stage of fibrosis was scored in wild-type (WT), $\mathrm{CCL}^{-/-}$, and $\mathrm{CCR}^{-/-}$mice after 4 to 6 weeks of TAA treatment ( $n=6$ to 18 samples per time point). E: Representative F $4 / 80^{+}$immunostaining from WT, $\mathrm{CCL}^{-/-}$, and $\mathrm{CCR}^{-/-}$mice after 1 week of TAA treatment. Data are presented as means $\pm \mathrm{SEM} .{ }^{*} P<0.05$ (naive versus TAA, 1 week versus 4 weeks TAA, and WT versus $\mathrm{CCL}^{-l-}$ ), ${ }^{* *} P<0.001$ (CCR2 $^{+}$population; naive versus TAA), Mann Whitney- $U$ test. Black arrows indicate monocyte accumulation at central vein.

the phenotype of these cells. The monocyte population in naive livers is comprised of Ly6 $\mathrm{C}^{\mathrm{hi}}$ and Ly6 $\mathrm{C}^{\mathrm{lo}}$ monocytes, which are found at a 70:30 ratio, respectively (Figure 7A). As anticipated, the Ly6 $\mathrm{C}^{\text {hi }}$ monocytes also were positive for chemokine (C-C motif) receptor $2\left(\mathrm{CCR} 2^{+}\right)$, whereas

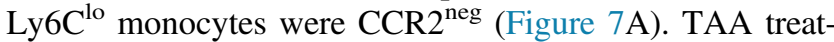
ment induced a substantial and proportionate increase in both $\mathrm{CCR} 2^{+}$and $\mathrm{CCR} 2^{\text {neg }}$ monocyte subsets in the liver at week 1, and this increase was maintained at week 4 (Figure 7A). Notably, after 4 weeks of TAA treatment, the proportion of CCR $2^{\text {neg }}$ monocytes expressing major histocompatibility complex class II significantly increased (61.8\% versus $80.5 \%$, naive versus 4 weeks, $P=0.029$, $n=4$ per group) indicative of their activation (Figure 7B). In contrast, major histocompatibility complex class II expression by $\mathrm{CCR} 2^{+}$monocytes was unchanged by TAA treatment. Of note, CCL2 (the primary CCR2 ligand) mRNA expression was increased significantly in the liver at 1 week and remained elevated thereafter, albeit at slightly reduced levels (Figure 7C). However, fibrosis was only partially abrogated in $\mathrm{CCL} 2^{-/-}$mice at week 4 , as assessed using a modified METAVIR scoring system (Figure 7D), even though a marked reduction in pericentral monocyte infiltration was noted at 1 week (Figure 7E). In contrast, $\mathrm{CCR} 2^{-1-}$ mice were not protected at either week 1 or 4 (Figure 7, D and E).

CSF-1 is important for the differentiation, proliferation, and survival of macrophages. ${ }^{28,29}$ Although both $\mathrm{CCR}^{+}$and $\mathrm{CCR} 2^{\text {neg }}$ monocyte populations express the CSF-1 receptor (CSF-1R), they exhibit distinct requirements for CSF-1. In agreement with our previous studies ${ }^{30}$ we confirmed that in a naive setting, CSF-1R blockade in vivo results in the depletion of the vast majority of the liver resident macrophages, and we here extended these findings by demonstrating the ablation of both Tim $4^{+}$Kupffer cells and Tim $4^{\text {neg }}$ BMDM (Figure 8A). We therefore next examined whether CSF-1R blockade during TAA treatment would disrupt the monocyte/macrophage differentiation pathway, resulting in the attenuation of liver injury. Concurrent treatment of mice with TAA and anti-CSF-1R mAb (M279) attenuated DR development and resulted in a significant reduction in collagen deposition and fibrosis score (Figure 8, B and C). We have reported previously that CSF-1R blockade with M279 results in the specific ablation of Ly6C ${ }^{\mathrm{lo}}$ monocytes and tissue resident macrophages in naive and fibrotic tissues. ${ }^{30,31}$ Consistent with these findings, although there was no significant reduction in total monocyte numbers in the blood or liver (data not shown), CSF-1R blockade resulted in a significant decrease in peripheral blood and liver Ly6 $\mathrm{C}^{\mathrm{lo}}$ monocytes and liver macrophages following TAA treatment (Figure 8, D-F).

\section{Discussion}

The present study demonstrates a previously unrecognized biphasic response to TAA-induced liver injury. Although the development of fibrosis and the DR previously have been reported to be contemporaneous, ${ }^{3,4}$ in this model of chronic liver disease, fibrogenesis began independently of the DR and was associated with an early and transient pericentral monocyte-enriched inflammatory infiltrate. Fibrosis progression and septation accelerated after apparent DR migration and formation of a HPC niche at the centrilobular sites of injury, with intimate association between HPC/cholangiocytes, $\mathrm{SMA}^{+}$myofibroblasts, and stromal 

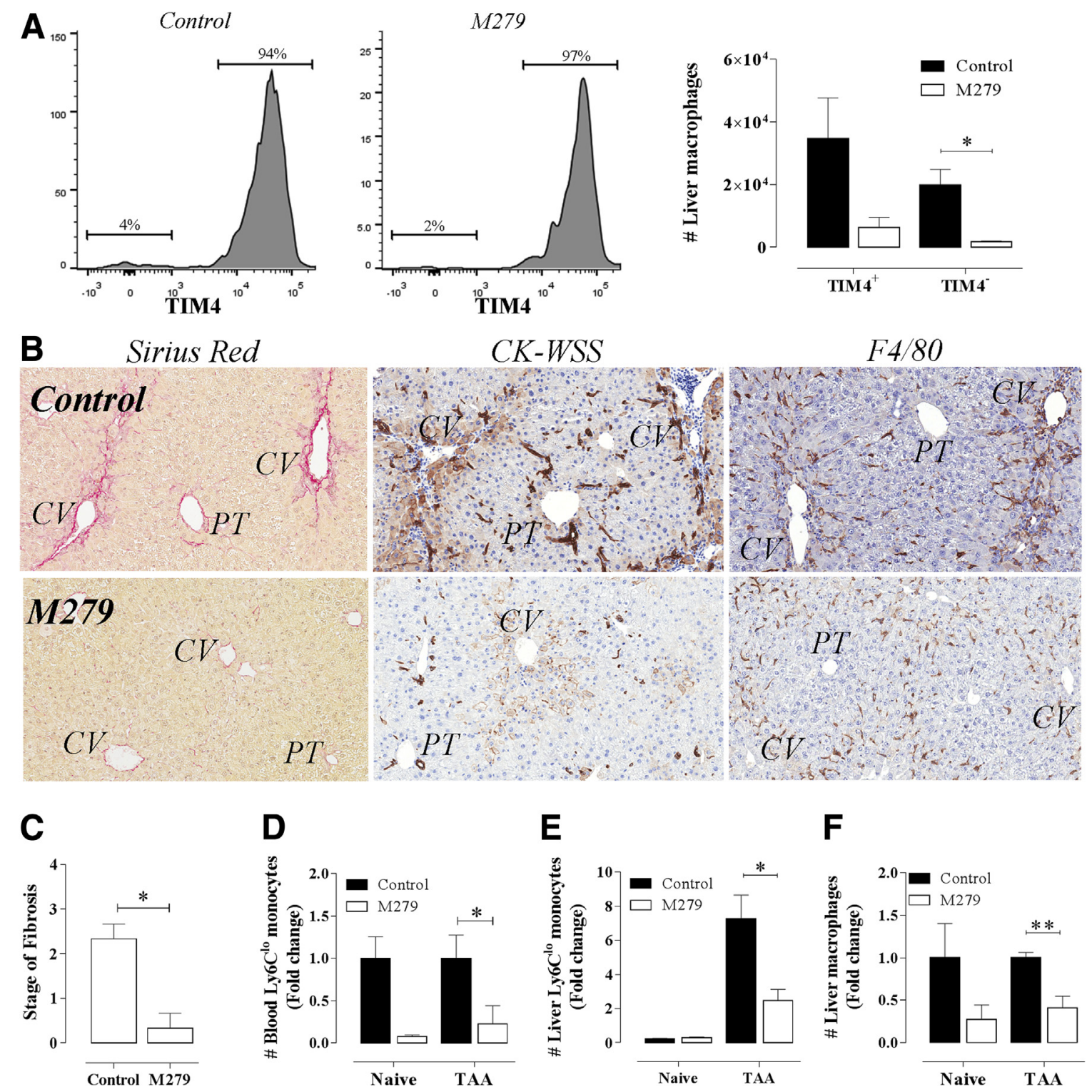

Figure 8 Colony-stimulating factor 1 (CSF-1) dependency in thioacetamide (TAA)-induced liver injury. A: Representative histograms and quantification of TIM4 ${ }^{+}$ and TIM4- macrophage populations following control (Rat IgG1) and CSF-1 blocking (M279) antibody treatment in naive C57BL/6 mice. B: Images of liver fibrosis (Sirius red), DR [wide-spectrum keratin (CK-WSS)], and F4/80 staining from 4 weeks TAA-treated mice following control or M279 antibody treatment. C: Stage of fibrosis was assessed using a modified METAVIR scoring system. D-F: Absolute numbers of Ly6 $\mathrm{C}^{\mathrm{lo}} / \mathrm{CCR}^{-}$peripheral blood monocytes (D), liver Ly6C ${ }^{\text {lo }} / \mathrm{CCR}^{-}$ monocytes (E), and liver macrophages (F) in naive and 4 weeks TAA-treated mice following administration of control antibody or M279 ( $n=2$ to 4 per group). Data are presented as means \pm SEM. ${ }^{*} P<0.05,{ }^{*} P<0.01$ (control versus M279), Mann Whitney $U$ test or unpaired $t$-test. CV, central vein; PT, portal tract.

components, such as collagens and inflammatory cells, particularly macrophages. After the expansion of the DR, fibrogenesis accelerated at an almost fivefold rate compared with early fibrosis. Peripheral blood monocytes initially were recruited to the parenchyma around central veins and after several weeks migrated into the lobules and differentiated into macrophages, which increasingly co-localized with the migrating DR. The majority of tissue resident macrophages turned over within 6 weeks. Finally, although CCL2 deficiency attenuated early monocyte infiltration and fibrosis, its contribution to progressive fibrosis was marginal and not mediated by CCR2. In contrast, we demonstrated that CSF-1 signaling is critical for the development and survival of CCR $2^{\text {neg }}$ monocytes and for the progression of fibrosis.

The liver contains a large population of long-lived tissue resident macrophages (Kupffer cells), in which mice appear to originate from yolk sac precursors and exhibit the capacity for self-renewal throughout adult life. ${ }^{32}$ In response to inflammation, this macrophage pool is expanded through the recruitment and differentiation of circulating monocytes. In this regard, using FITC dextran, we demonstrated that a liver insult rapidly induces the infiltration of monocytes into centrilobular regions of injury where they are poised to 
differentiate into macrophages to replace tissue resident macrophages. The transient pericentral $\mathrm{CCR}^{+}$and CCR2 $2^{\text {neg }}$ monocytic infiltration was associated with elevated liver $\mathrm{Ccl} 2$ and early phase collagen deposition in this region. However, CCL2 deficiency only partially abrogated fibrosis at week 4 , and $\mathrm{CCR} 2^{-1-}$ mice were not protected at either week 1 or 4 (Figure 5). Our data are congruous with several studies that demonstrated a variable contribution of the CCR2/CCL2 axis to liver injury. ${ }^{12,33,34}$ Notably, neither CCR2 nor CCL2 were found to mediate fibrosis in chronic graft-versus-host disease after hematopoietic stem cell transplantation, whereas CSF-1 dependent macrophages were pathogenic. ${ }^{30}$ Several other chemokine receptors such as CCR1, CCR5, CCR6, and CCR8 also exhibit the capacity to drive monocyte chemotaxis. ${ }^{35}$ Of note, signaling through CCR5 on $\mathrm{Ly}_{6} \mathrm{C}^{\mathrm{lo}}\left(\mathrm{CCR} 2^{\text {neg }}\right)$ monocytes has been reported to promote their accumulation in inflamed tissues ${ }^{36}$ and our data demonstrated that CCR5 mRNA was upregulated after 1 and 4 weeks of TAA treatment. However, the functional contribution of CCR5 remains to be shown, and it is likely that multiple chemokine receptor/ligand pairs contribute to monocyte recruitment and subsequent fibrosis. Thus, additional investigations are required.

Previous studies have demonstrated that fibrosis develops in close association with the DR in a wide range of chronic liver diseases. ${ }^{4,5,37}$ The composition of the matrix in the DR niche is an important regulator of the HPC response, but the temporal and causal relationship between collagen deposition and HPC expansion is not well understood. Typically, HPC are surrounded by laminin, which, unlike collagen, maintains progenitor and cholangiocytic phenotype. ${ }^{16,38} \mathrm{In}$ agreement with an earlier study in the choline-deficient, ethionine-supplemented diet model, ${ }^{8}$ we clearly demonstrated that fibrosis preceded the development of the DR. Although deposited collagen appeared to facilitate HPC expansion into the liver lobule in the choline-deficient, ethionine-supplemented diet model and has been proposed to be a prerequisite for expansion, in the TAA model, the initiation sites of these two processes were spatially distinct. Whether laminin, or another matrix component, chaperones the migrating DR in this model is not known. During the second phase of injury, however, the development of a typical HPC niche and the migration of the DR to the site of injury was associated with accelerated fibrosis and septation. This suggests that there may be multiple mechanisms driving fibrosis during chronic liver injury and supports observations in steatohepatitis, for example, in which fibrosis occurs in both centrilobular and periportal areas. ${ }^{39}$ In pediatric steatohepatitis, centrilobular fibrosis was associated with local inflammatory activity, whereas portal fibrosis correlated with an expanded DR. ${ }^{1}$ In support of a profibrogenic role, epithelial cells of the DR express multiple chemotactic and profibrogenic proteins. ${ }^{7,40,41}$ Additionally, the intimate association between the DR, hepatic stellate cells, inflammatory cells, collagen, and the increasing frequency of DR-macrophage interaction provide further evidence for this notion. Notably, it appears likely that significant metaplasia can occur within the ductular niche, so that not only HPC but also biliary epithelium ${ }^{42}$ and even hepatic stellate cells ${ }^{43}$ may contribute to hepatocyte regeneration.

Microarray data showed temporal changes in gene expression of multiple immune mediators and extracellular matrix components. As anticipated, genes associated with monocyte recruitment and macrophage function were induced early in the time course, whereas changes in expression of matrix metalloproteinases and multiple species of collagen were associated with the later time points. Importantly, the array data indicated a decrease in the expression of Kupffer cell-associated molecules Clec $4 f$ and Timd 4 after TAA treatment, suggestive of a decrease in this liver macrophage population. We validated the array data using flow cytometric analysis of Tim4 expression, confirming the time-dependent loss of Tim $4^{+}$Kupffer cells and their concurrent replacement by BMDM. Of note, the tumor necrosis factor-like weak inducer of apoptosis receptor was upregulated early and expression maintained throughout the time course. The primary function of tumor necrosis factor-like weak inducer of apoptosis receptor in liver fibrosis is reported to be in the activation of HPC and expansion of the $\mathrm{DR}^{18}$; however, the early induction of the receptor and its continued expression during a period of minimal DR activity suggests a broader functional role for this molecule. The late induction of IL-28ra, the receptor for interferon $\lambda$, expression is intriguing, as interferon $\lambda$ polymorphisms are reported to correlate strongly with liver fibrosis in an etiology-independent manner. ${ }^{44}$ These data thus provide a guide to relevant time points for investigation of the function of different fibrotic mediators in this model.

Finally, we have demonstrated a crucial role for CSF-1 in the development of the DR niche and for progressive fibrosis in the TAA model. CSF-1 is a master regulator of mononuclear phagocyte development, differentiation, maturation, and function during homeostasis. ${ }^{31,45,46}$ Current dogma holds that it is the CCR $2^{\text {neg }} \mathrm{Ly} 6 \mathrm{C}^{\mathrm{lo}} \mathrm{F} 4 / 80^{+} \mathrm{CD} 11 \mathrm{~b}^{\mathrm{hi}}$ monocytes that give rise to tissue resident macrophages. Previously, we have demonstrated in vivo that in the absence of CSF-1, tissue resident macrophages, and peripheral blood $\mathrm{CCR} 2^{\text {neg }}$ monocytes are reduced, whereas circulating $\mathrm{CCR} 2^{+}$monocyte numbers are increased. ${ }^{31}$ Thus, CSF-1 may promote the differentiation of CCR2 ${ }^{+}$ monocytes into CCR2 ${ }^{\text {neg }}$ monocytes, which are the bone marrow-derived precursors that repopulate tissue macrophages. In addition, recently we have demonstrated the capacity for CSF-1R blockade to deplete tissue resident macrophages and attenuate skin and lung fibrosis associated with chronic graft-versus-host disease. ${ }^{30}$

Collectively, the data suggest that in response to TAA, CCL2 is required to recruit $\mathrm{CCR} 2^{+}$monocytes into the liver, and that these monocytes directly contribute to earlyphase fibrosis. The marked attenuation of fibrosis with 
concurrent administration of anti-CSF-1R at the time of toxic injury suggests a key role for differentiated macrophages in the development of a mature DR and fibrogenesis. We propose that CSF-1 plays a critical role in driving the differentiation of $\mathrm{CCR} 2^{+}$monocytes into $\mathrm{CCR} 2^{\text {neg }}$ monocytes and their subsequent differentiation into pathogenic liver macrophages, highlighting the potential of CSF-1 blockade as a potent antifibrotic for chronic liver disease.

\section{Acknowledgments}

M.Me. conceived and designed the study; acquired, analyzed, and interpreted data; and wrote the manuscript. V.L.G. acquired, analyzed, and interpreted data, and wrote the manuscript. K.A.A., G.C.M., and G.M.B. acquired, analyzed, and interpreted data. L.B. revised the manuscript. K.E.L. acquired data. M.Ma. and L.L.T. provided technical support. K.M.I. analyzed and interpreted data. G.R.H. analyzed and interpreted data and provided material support. A.D.C. analyzed and interpreted data and revised the manuscript. E.E.P. analyzed and interpreted data, provided funding, and revised the manuscript. K.P.A.M. conceived and designed the study, analyzed and interpreted data, provided funding, and revised the manuscript. K.P.A.M. is the guarantor of this work and, as such, had full access to all data and takes responsibility for data integrity and accuracy of data interpretation.

\section{Supplemental Data}

Supplemental material for this article can be found at http://dx.doi.org/10.1016/j.ajpath.2015.10.029.

\section{References}

1. Skoien R, Richardson MM, Jonsson JR, Powell EE, Brunt EM, Neuschwander-Tetri BA, Bhathal PS, Dixon JB, O’Brien PE, Tilg H, Moschen AR, Baumann U, Brown RM, Couper RT, Manton ND, Ee LC, Weltman M, Clouston AD: Heterogeneity of fibrosis patterns in non-alcoholic fatty liver disease supports the presence of multiple fibrogenic pathways. Liver Int 2013, 33:624-632

2. Gouw AS, Clouston AD, Theise ND: Ductular reactions in human liver: diversity at the interface. Hepatology 2011, 54:1853-1863

3. Clouston AD, Powell EE, Walsh MJ, Richardson MM, Demetris AJ, Jonsson JR: Fibrosis correlates with a ductular reaction in hepatitis C: roles of impaired replication, progenitor cells and steatosis. Hepatology 2005, 41:809-818

4. Richardson MM, Jonsson JR, Powell EE, Brunt EM, NeuschwanderTetri BA, Bhathal PS, Dixon JB, Weltman MD, Tilg H, Moschen AR, Purdie DM, Demetris AJ, Clouston AD: Progressive fibrosis in nonalcoholic steatohepatitis: association with altered regeneration and a ductular reaction. Gastroenterology 2007, 133:80-90

5. Wood MJ, Gadd VL, Powell LW, Ramm GA, Clouston AD: Ductular reaction in hereditary hemochromatosis: the link between hepatocyte senescence and fibrosis progression. Hepatology 2014, $59: 848-857$

6. Roskams T, Desmet V: Ductular reaction and its diagnostic significance. Semin Diagn Pathol 1998, 15:259-269
7. Williams MJ, Clouston AD, Forbes SJ: Links between hepatic fibrosis, ductular reaction, and progenitor cell expansion. Gastroenterology 2014, 146:349-356

8. Van Hul N, Abarca-Quinones J, Sempoux C, Horsmans Y, Leclercq IA: Relation between liver progenitor cell expansion and extracellular matrix deposition in a CDE-induced murine model of chronic liver injury. Hepatology 2009, 49:1625-1635

9. Friedman SL: Mac the knife? Macrophages- the double-edged sword of hepatic fibrosis. J Clin Invest 2005, 115:29-32

10. Fallowfield JA, Mizuno M, Kendall TJ, Constandinou CM, Benyon RC, Duffield JS, Iredale JP: Scar-associated macrophages are a major source of hepatic matrix metalloproteinase-13 and facilitate the resolution of murine hepatic fibrosis. J Immunol 2007, 178: $5288-5295$

11. Tacke F, Zimmermann HW: Macrophage heterogeneity in liver injury and fibrosis. J Hepatol 2014, 60:1090-1096

12. Karlmark KR, Weiskirchen R, Zimmermann HW, Gassler N, Ginhoux F, Weber C, Merad M, Luedde T, Trautwein C, Tacke F: Hepatic recruitment of the inflammatory Gr1+ monocyte subset upon liver injury promotes hepatic fibrosis. Hepatology 2009, 50:261-274

13. Ramachandran P, Pellicoro A, Vernon MA, Boulter L, Aucott RL, Ali A, Hartland SN, Snowdon VK, Cappon A, Gordon-Walker TT, Williams MJ, Dunbar DR, Manning JR, van RN, Fallowfield JA, Forbes SJ, Iredale JP: Differential Ly-6C expression identifies the recruited macrophage phenotype, which orchestrates the regression of murine liver fibrosis. Proc Natl Acad Sci U S A 2012, 109: E3186-E3195

14. Gadd VL, Melino M, Roy S, Horsfall L, O'Rourke P, Williams MR, Irvine KM, Sweet MJ, Jonsson JR, Clouston AD, Powell EE: Portal, but not lobular, macrophages express matrix metalloproteinase-9: association with the ductular reaction and fibrosis in chronic hepatitis C. Liver Int 2013, 33:569-579

15. Gadd VL, Skoien R, Powell EE, Fagan KJ, Winterford C, Horsfall L, Irvine $\mathrm{K}$, Clouston AD: The portal inflammatory infiltrate and ductular reaction in human nonalcoholic fatty liver disease. Hepatology 2014, 59:1393-1405

16. Lorenzini S, Bird TG, Boulter L, Bellamy C, Samuel K, Aucott R, Clayton E, Andreone P, Bernardi M, Golding M, Alison MR, Iredale JP, Forbes SJ: Characterisation of a stereotypical cellular and extracellular adult liver progenitor cell niche in rodents and diseased human liver. Gut 2010, 59:645-654

17. Van Hul N, Lanthier N, Espanol Suner R, Abarca Quinones J, van Rooijen N, Leclercq I: Kupffer cells influence parenchymal invasion and phenotypic orientation, but not the proliferation, of liver progenitor cells in a murine model of liver injury. Am J Pathol 2011, 179: $1839-1850$

18. Bird TG, Lu WY, Boulter L, Gordon-Keylock S, Ridgway RA, Williams MJ, Taube J, Thomas JA, Wojtacha D, Gambardella A, Sansom OJ, Iredale JP, Forbes SJ: Bone marrow injection stimulates hepatic ductular reactions in the absence of injury via macrophagemediated TWEAK signaling. Proc Natl Acad Sci U S A 2013, 110: 6542-6547

19. Boulter L, Govaere O, Bird TG, Radulescu S, Ramachandran P, Pellicoro A, Ridgway RA, Seo SS, Spee B, Van Rooijen N, Sansom OJ, Iredale JP, Lowell S, Roskams T, Forbes SJ: Macrophagederived Wnt opposes Notch signaling to specify hepatic progenitor cell fate in chronic liver disease. Nat Med 2012, 18:572-579

20. Elsharkawy AM, Mann DA: Nuclear factor-kappaB and the hepatic inflammation-fibrosis-cancer axis. Hepatology 2007, 46:590-597

21. Fagan KJ, Pretorius CJ, Horsfall LU, Irvine KM, Wilgen U, Choi K, Fletcher LM, Tate J, Melino M, Nusrat S, Miller GC, Clouston AD, Ballard E, O'Rourke P, Lampe G, Ungerer JP, Powell EE: ELF score $\geq 9.8$ indicates advanced hepatic fibrosis and is influenced by age, steatosis and histological activity. Liver Int 2015, 35:1673-1681

22. Blom KG, Qazi MR, Matos JB, Nelson BD, DePierre JW, AbediValugerdi M: Isolation of murine intrahepatic immune cells employing a modified procedure for mechanical disruption and 
functional characterization of the $\mathrm{B}, \mathrm{T}$ and natural killer $\mathrm{T}$ cells obtained. Clin Exp Immunol 2009, 155:320-329

23. Dunning MJ, Smith ML, Ritchie ME, Tavare $S$ : beadarray: $r$ classes and methods for Illumina bead-based data. Bioinformatics 2007, 23: $2183-2184$

24. Barbosa-Morais NL, Dunning MJ, Samarajiwa SA, Darot JF, Ritchie ME, Lynch AG, Tavare S: A re-annotation pipeline for Illumina BeadArrays: improving the interpretation of gene expression data. Nucleic Acids Res 2010, 38:e17

25. Wu D, Smyth GK: Camera: a competitive gene set test accounting for inter-gene correlation. Nucleic Acids Res 2012, 40:e133

26. Yang CY, Chen JB, Tsai TF, Tsai YC, Tsai CY, Liang PH, Hsu TL, Wu CY, Netea MG, Wong CH, Hsieh SL: CLEC4F is an inducible C-type lectin in F4/80-positive cells and is involved in alphagalactosylceramide presentation in liver. PLoS One 2013, 8:e65070

27. Zigmond E, Samia-Grinberg S, Pasmanik-Chor M, Brazowski E, Shibolet O, Halpern Z, Varol C: Infiltrating monocyte-derived macrophages and resident kupffer cells display different ontogeny and functions in acute liver injury. J Immunol 2014, 193:344-353

28. Bonifer C, Hume DA: The transcriptional regulation of the colonystimulating factor 1 receptor (csf1r) gene during hematopoiesis. Front Biosci 2008, 13:549-560

29. Stanley ER, Berg KL, Einstein DB, Lee PS, Pixley FJ, Wang Y, Yeung YG: Biology and action of colony-stimulating factor-1. Mol Reprod Dev 1997, 46:4-10

30. Alexander KA, Flynn R, Lineburg KE, Kuns RD, Teal BE, Olver SD, Lor M, Raffelt NC, Koyama M, Leveque L, Le Texier L, Melino M, Markey KA, Varelias A, Engwerda C, Serody JS, Janela B, Ginhoux F, Clouston AD, Blazar BR, Hill GR, MacDonald KP: CSF-1-dependant donor-derived macrophages mediate chronic graft-versus-host disease. J Clin Invest 2014, 124:4266-4280

31. MacDonald KP, Palmer JS, Cronau S, Seppanen E, Olver S, Raffelt NC, Kuns R, Pettit AR, Clouston A, Wainwright B, Branstetter D, Smith J, Paxton RJ, Cerretti DP, Bonham L, Hill GR, Hume DA: An antibody against the colony-stimulating factor 1 receptor depletes the resident subset of monocytes and tissue- and tumorassociated macrophages but does not inhibit inflammation. Blood 2010, 116:3955-3963

32. Hashimoto D, Chow A, Noizat C, Teo P, Beasley MB, Leboeuf M, Becker CD, See P, Price J, Lucas D, Greter M, Mortha A, Boyer SW, Forsberg EC, Tanaka M, van Rooijen N, Garcia-Sastre A, Stanley ER, Ginhoux F, Frenette PS, Merad M: Tissue-resident macrophages selfmaintain locally throughout adult life with minimal contribution from circulating monocytes. Immunity 2013, 38:792-804

33. Seki E, de Minicis S, Inokuchi S, Taura K, Miyai K, van Rooijen N, Schwabe RF, Brenner DA: CCR2 promotes hepatic fibrosis in mice. Hepatology 2009, 50:185-197

34. Baeck C, Wehr A, Karlmark KR, Heymann F, Vucur M, Gassler N, Huss S, Klussmann S, Eulberg D, Luedde T, Trautwein C, Tacke F: Pharmacological inhibition of the chemokine CCL2 (MCP-1) diminishes liver macrophage infiltration and steatohepatitis in chronic hepatic injury. Gut 2012, 61:416-426
35. Tacke F, Alvarez D, Kaplan TJ, Jakubzick C, Spanbroek R, Llodra J, Garin A, Liu J, Mack M, van Rooijen N, Lira SA, Habenicht AJ, Randolph GJ: Monocyte subsets differentially employ CCR2, CCR5, and CX3CR1 to accumulate within atherosclerotic plaques. J Clin Invest 2007, 117:185-194

36. Combadiere C, Potteaux S, Rodero M, Simon T, Pezard A, Esposito B, Merval R, Proudfoot A, Tedgui A, Mallat Z: Combined inhibition of CCL2, CX3CR1, and CCR5 abrogates Ly6C(hi) and Ly6C(lo) monocytosis and almost abolishes atherosclerosis in hypercholesterolemic mice. Circulation 2008, 117:1649-1657

37. Roskams T, Yang SQ, Koteish A, Durnez A, DeVos R, Huang X, Achten R, Verslype C, Diehl AM: Oxidative stress and oval cell accumulation in mice and humans with alcoholic and nonalcoholic fatty liver disease. Am J Pathol 2003, 163:1301-1311

38. Paku S, Schnur J, Nagy P, Thorgeirsson SS: Origin and structural evolution of the early proliferating oval cells in rat liver. Am J Pathol 2001, 158:1313-1323

39. Kleiner DE, Brunt EM: Nonalcoholic fatty liver disease: pathologic patterns and biopsy evaluation in clinical research. Semin Liver Dis 2012, 32:3-13

40. Wang X, Lopategi A, Ge X, Lu Y, Kitamura N, Urtasun R, Leung TM, Fiel MI, Nieto N: Osteopontin induces ductular reaction contributing to liver fibrosis. Gut 2014, 63:1805-1818

41. Pi L, Robinson PM, Jorgensen M, Oh SH, Brown AR, Weinreb PH, Trinh TL, Yianni P, Liu C, Leask A, Violette SM, Scott EW, Schultz GS, Petersen BE: Connective tissue growth factor and integrin alphavbeta6: a new pair of regulators critical for ductular reaction and biliary fibrosis in mice. Hepatology 2015, 61:678-691

42. Rodrigo-Torres D, Affo S, Coll M, Morales-Ibanez O, Millan C, Blaya D, Alvarez-Guaita A, Rentero C, Lozano JJ, Maestro MA, Solar M, Arroyo V, Caballeria J, van Grunsven LA, Enrich C, Gines P, Bataller R, Sancho-Bru P: The biliary epithelium gives rise to liver progenitor cells. Hepatology 2014, 60:1367-1377

43. Kordes C, Sawitza I, Gotze S, Herebian D, Haussinger D: Hepatic stellate cells contribute to progenitor cells and liver regeneration. J Clin Invest 2014, 124:5503-5515

44. Eslam M, Hashem AM, Leung R, Romero-Gomez M, Berg T, Dore GJ, Chan HLK, Irving WL, Sheridan D, Abate ML, Adams LA, Mangia A, Weltman M, Bugianesi E, Spengler U, Shaker O, Fischer J, Mollison L, Cheng W, Powell E, Nattermann J, Riordan S, McLeod D, Armstrong NJ, Douglas MW, Liddle C, Booth DR, George J, Ahlenstiel G; the International Hepatitis C Genetics Consortium (IHCGC): Interferon- $\lambda$ rs12979860 genotype and liver fibrosis in viral and non-viral chronic liver disease. Nat Commun 2015, 6:6422

45. Hume DA, MacDonald KP: Therapeutic applications of macrophage colony-stimulating factor- 1 (CSF-1) and antagonists of CSF-1 receptor (CSF-1R) signaling. Blood 2012, 119:1810-1820

46. MacDonald KP, Rowe V, Bofinger HM, Thomas R, Sasmono T, Hume DA, Hill GR: The colony-stimulating factor 1 receptor is expressed on dendritic cells during differentiation and regulates their expansion. J Immunol 2005, 175:1399-1405 